\title{
Acoustic Investigation of Jet Mixing Noise in Dual Stream Nozzles
}

Abbas Khavaran

ASRC Aerospace, Cleveland, Ohio

Milo D. Dahl

Glenn Research Center, Cleveland, Ohio 


\section{NASA STI Program . . . in Profile}

Since its founding, NASA has been dedicated to the advancement of aeronautics and space science. The NASA Scientific and Technical Information (STI) program plays a key part in helping NASA maintain this important role.

The NASA STI Program operates under the auspices of the Agency Chief Information Officer. It collects, organizes, provides for archiving, and disseminates NASA's STI. The NASA STI program provides access to the NASA Aeronautics and Space Database and its public interface, the NASA Technical Reports Server, thus providing one of the largest collections of aeronautical and space science STI in the world. Results are published in both non-NASA channels and by NASA in the NASA STI Report Series, which includes the following report types:

- TECHNICAL PUBLICATION. Reports of completed research or a major significant phase of research that present the results of NASA programs and include extensive data or theoretical analysis. Includes compilations of significant scientific and technical data and information deemed to be of continuing reference value. NASA counterpart of peer-reviewed formal professional papers but has less stringent limitations on manuscript length and extent of graphic presentations.

- TECHNICAL MEMORANDUM. Scientific and technical findings that are preliminary or of specialized interest, e.g., quick release reports, working papers, and bibliographies that contain minimal annotation. Does not contain extensive analysis.

- CONTRACTOR REPORT. Scientific and technical findings by NASA-sponsored contractors and grantees.
- CONFERENCE PUBLICATION. Collected papers from scientific and technical conferences, symposia, seminars, or other meetings sponsored or cosponsored by NASA.

- SPECIAL PUBLICATION. Scientific, technical, or historical information from NASA programs, projects, and missions, often concerned with subjects having substantial public interest.

- TECHNICAL TRANSLATION. Englishlanguage translations of foreign scientific and technical material pertinent to NASA's mission.

Specialized services also include creating custom thesauri, building customized databases, organizing and publishing research results.

For more information about the NASA STI program, see the following:

- Access the NASA STI program home page at http://www.sti.nasa.gov

- E-mail your question via the Internet to help@ sti.nasa.gov

- Fax your question to the NASA STI Help Desk at $443-757-5803$

- Telephone the NASA STI Help Desk at 443-757-5802

- Write to: NASA Center for AeroSpace Information (CASI) 7115 Standard Drive Hanover, MD 21076-1320 
NASA/TM-2012-217226

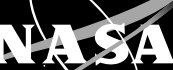

Acoustic Investigation of Jet Mixing Noise in Dual Stream Nozzles

Abbas Khavaran

ASRC Aerospace, Cleveland, Ohio

Milo D. Dahl

Glenn Research Center, Cleveland, Ohio

Prepared for the

17th Aeroacoustics Conference

cosponsored by the American Institute of Aeronautics and Astronautics and

the Confederation of European Aerospace Societies

Portland, Oregon, June 5-8, 2011

National Aeronautics and

Space Administration

Glenn Research Center

Cleveland, Ohio 44135 


\section{Acknowledgments}

This work is supported by the Subsonic Fixed Wing and Supersonic Projects under the NASA Fundamental Aeronautics Program.

This report is a formal draft or working paper, intended to solicit comments and ideas from a technical peer group.

This work was sponsored by the Fundamental Aeronautics Program at the NASA Glenn Research Center.

Level of Review: This material has been technically reviewed by technical management.

Available from

NASA Center for Aerospace Information 7115 Standard Drive

Hanover, MD 21076-1320
National Technical Information Service 5301 Shawnee Road Alexandria, VA 22312

Available electronically at http://www.sti.nasa.gov 


\title{
Acoustic Investigation of Jet Mixing Noise in Dual Stream Nozzles
}

\author{
Abbas Khavaran \\ ASRC Aerospace Corporation \\ Cleveland, Ohio 44135 \\ Milo D. Dahl \\ National Aeronautics and Space Administration \\ Glenn Research Center \\ Cleveland, Ohio 44135
}

\begin{abstract}
In an earlier study, a prediction model for jet noise in dual stream jets was proposed that is founded on velocity scaling laws in single stream jets and similarity features of the mean velocity and turbulent kinetic energy in dual stream flows. The model forms a composite spectrum from four component singlestream jets each believed to represent noise-generation from a distinct region in the actual flow. While the methodology worked effectively at conditions considered earlier, recent examination of acoustic data at some unconventional conditions indicate that further improvements are necessary in order to expand the range of applicability of the model. The present work demonstrates how these predictions compare with experimental data gathered by NASA and industry for the purpose of examining the aerodynamic and acoustic performance of such nozzles for a wide range of core and fan stream conditions. Of particular interest are jets with inverted velocity and temperature profiles and the appearance of a second spectral peak at small aft angles to the jet under such conditions. It is shown that a four-component spectrum succeeds in modeling the second peak when the aft angle refraction effects are properly incorporated into the model. A tradeoff of noise emission takes place between two turbulent regions identified as transition and fully mixed regions as the fan stream velocity exceeds that of the core stream. The effect of nozzle discharge coefficients will also be discussed.
\end{abstract}

\section{Nomenclature}

$\begin{array}{ll}A & \text { Jet exit area } \\ B & \text { Intercept parameter } \\ c & \text { Sound speed } \\ D & \text { Jet diameter } \\ D_{i} & \text { Inner diameter in the secondary jet } \\ D_{e} & \text { Effective diameter } \\ \hat{D} & \text { Modified diameter } \\ c_{p} & \text { Specific heat at constant pressure } \\ f, f^{*} & \text { Frequency, characteristic frequency } \\ m^{g} & \text { Mass flow rate } \\ M & \text { Mach number } \\ n & \text { Velocity exponent } \\ T, T^{\mathrm{o}} & \text { Static or stagnation temperatures } \\ U & \text { Mean axial velocity } \\ \alpha & \text { Amplitude adjustment factor } \\ \delta & \text { Diameter ratio }\left(D_{i} / D_{p}\right)\end{array}$


$\gamma \quad$ Specific heat ratio

$\lambda_{A}, \lambda_{V} \quad$ Area and velocity ratio - secondary divided by primary

$\lambda_{T} \quad$ Static temperature ratio - primary divided by secondary

$\theta \quad$ Polar angle from inlet axis

$\rho \quad$ Density

$\xi \quad$ Normalized frequency $\left(f / f^{*}\right)$

Subscripts

$p \quad$ Primary jet (core)

$s \quad$ Secondary jet (bypass)

e Transition jet

$m \quad$ Fully mixed jet

$\infty \quad$ Ambient conditions

Superscripts

(p) Primary jet condition

(s) Secondary jet condition

(m) Mixed jet condition

\subsection{Introduction}

In an attempt to develop a robust and effective noise prediction methodology for turbofan engines, semi-empirical models have been proposed in a number of previous studies that address both jet mixing noise and the broadband shock associated noise under static and flight conditions. Such models use some form of physical scaling law, and regard the far field jet noise as a superposition of a number of uncorrelated spectral components, each with a distinctive spectral peak attributed to a particular source region in a jet. As expected, calibration of scaling laws relies heavily on far field acoustic measurements at a range of temperatures and pressures of interest for core and bypass streams. Details of the nozzle geometry, for example, noise suppression devices and installation effects such as center plugs and pylons, present additional parameters that impact noise. A justification for the utility of such predictions tools becomes evident in conjunction with multi-disciplinary design, analysis and optimization (MDAO) efforts that address aerodynamic performance, fuel efficiency, NOx emissions, and noise in the design and development of future commercial aircraft. High fidelity tools, applicable to each aspect of design in isolation, may not be computationally effective in an iterative fashion in an MDAO environment. Jet noise prediction models that use variants of the acoustic analogy theory are computationally intensive and require dedicated flow solvers to provide input for jet noise prediction in heated flows.

An example of a semi-empirical prediction code in aeroacoustics is the Aircraft Noise Prediction Program (ANOPP) (Ref. 1). It is a conglomerate of a number of functional modules, each conducting noise prediction on a model calibrated to a particular component of propulsion or airframe noise. Jet related noise modules in ANOPP were primarily developed by Stone et al. (Refs. 2 and 3) and have evolved with time to respond to new parameters and engine operating conditions. Stone et al. used a so-called hybrid experimental/empirical model to construct a three-component jet noise spectrum. These three noise components are attributed to the primary (core), secondary (bypass), and the fully mixed flow regions. Each component deploys a general 8th power velocity exponent when jets are unheated. A density exponent correction factor, as proposed by Ahuja and Bushell (Ref. 4), lowers this velocity exponent to 5 and 6 under heated conditions. 
Fisher et al. (Refs. 5 and 6) pioneered a jet noise scaling approach in dual stream flows from a fluid mechanics perspective. In the light of velocity and turbulence measurements, they divided a coaxial dual stream jet into several noise-generating segments based on similarity arguments. These noise-producing regions have some resemblance to those suggested by Stone, although their noise modeling details were different. They later enhanced the source model (Ref. 6) using a dipole-equivalent correction term that represented the temperature effect in the transition region of the dual stream jet. Tester and Fisher extended this model to coaxial jets with internal mixing, and showed that a two-source model, representing the transition and fully mixed regions, provided a good prediction in such flows. Using appropriate filters that reduced the low frequency amplitude in the mixed region, and enhanced the high frequency noise in the transition region, they were able to model the noise benefit/penalty in the forced mixers when the primary flow consisted of a lobed nozzle configuration (Refs. 7 to 9). These studies were limited in their scope and applicability of the velocity, area, and temperature ratio between the two streams, and did not examine unconventional velocity and temperature profiles that impact the peak amplitude as well as the high frequency noise at small aft angles that results from the span-wise inversion in mean velocity and/or temperature.

Noise component modeling considered in the current study resembles those suggested by Fisher et al., however component spectra are evaluated using a more general rule commonly known as the velocity power laws of jet noise. Velocity power laws are defined in terms of two empirical parameters - velocity exponent $n$ and intercept factor $B$. These parameters depend on jet temperature and observer angle and make it possible to scale the jet noise spectra in single stream jets from one set of operating conditions to the next. In order to determine parameters $n$ and $B$ for single stream jets, an extensive matrix of narrowband ( $5 \mathrm{~Hz}$ bandwidth) jet noise data acquired at the Small Hot Jet Acoustic Rig (SHJAR) (Refs. 10 and 11) at the NASA Glenn Research Center were examined in an earlier study (Ref. 12). A least-squares fit was implemented on the sound pressure level at each angle, and at exit velocity $U$ using $10 \log \left(U / c_{\infty}\right)$ as the dependent variable. The slope $n\left(\theta, T^{\circ}\right)$ and intercept $B\left(\theta, T^{\circ}\right)$ were subsequently evaluated at angle $\theta$ and stagnation temperature $T^{\circ}$. The set of jet operating conditions selected at each interpolation point were screened carefully to achieve a good fit. The jet conditions, interpolation points, and the confidence bands for parameters $n$ and $B$ are discussed in Reference 12. Figure 1 in Reference 13 shows the velocity scaling law parameters $n$ and $B$ at a range of angles and temperatures of common interest.

The idea of extending single-stream jet noise scaling laws to dual stream coannular jets is based on a constructive superposition of four single stream jets (Ref. 13). Each single stream jet, herein referred to as a component, is intended to capture noise emission from a distinct turbulent region contributing to the far field noise. Jet mixing noise is evaluated when velocity $U$, temperature $T^{\circ}$, and diameter $D$, for each of the four components, are supplied as input to a module that implements the scaling law. Additionally, spectral filters are designed to highlight the scales of turbulence associated with each noise component. Following the filtering process a superposition is carried out to form a composite spectrum.

The dual stream jet noise prediction model developed in a previous work (Ref. 13) is briefly reviewed in Section 2. Sample calculations are presented using conventional (normal velocity and temperature profiles) as well as inverted velocity and temperature profiles. Arguments based on refraction phenomena are presented in Section 3 to explain the dual peak character in the spectrum at small aft angles under the latter condition. Modifications that help improve the predictions are presented in Section 4, followed by examination of the model in Section 5. A summary of the results and direction for future work is provided in Section 6.

\subsection{A Dual Stream Jet Noise Model}

Following the arguments presented in Reference 13, a dual stream jet may be divided into 4 zones within three regions as sketched in Figure 1. The initial mixing region consists of two zones that reflect the mixing between the primary and the secondary streams (shown in pink), and the mixing between the secondary and the ambient streams (shown in blue). A transition region where the two mixing layers 


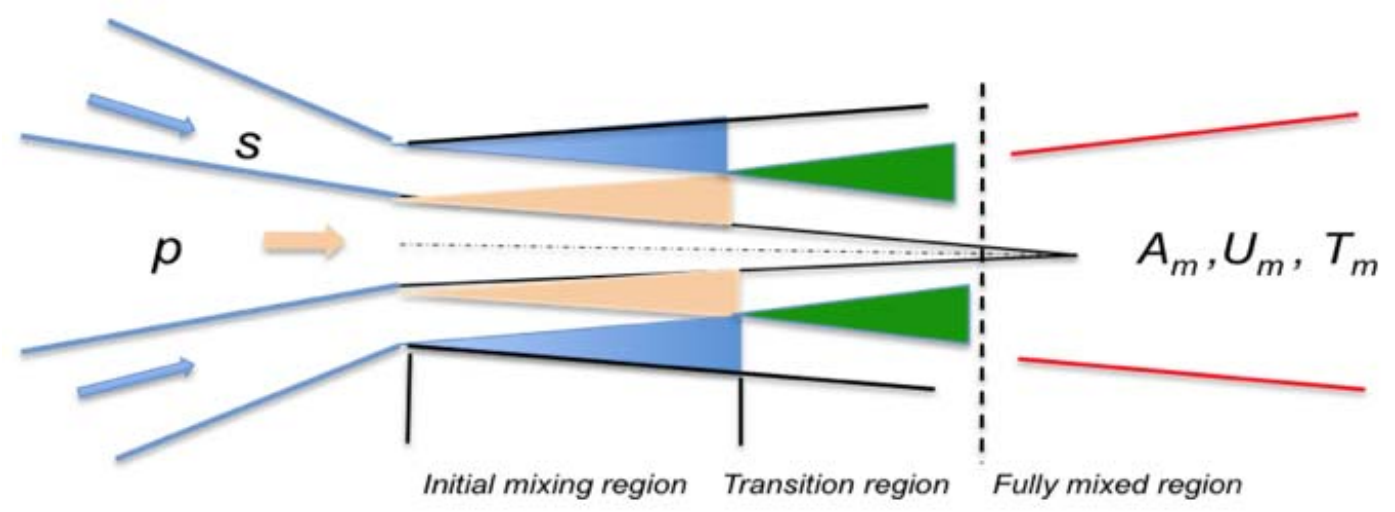

Figure 1.-Schematic of a dual stream jet showing mixing zones primary/bypass, bypass/ambient, the transition, and the fully mixed region.

merge, and subsequently a fully mixed region further downstream follow this initial mixing region. Noise generation from each of the four zones is addressed as a component (single stream) jet with three parameters $U, T^{\circ}$ and $D$. Herein, the primary, secondary, and the fully mixed streams are denoted using subscripts $p, s$ and $m$ respectively. The one-dimensional conservation equations plus the equation of state (assuming a constant static pressure) are used to evaluate the fully mixed jet conditions as discussed in Reference 13.

Using the ratios

$$
\lambda_{V} \equiv \frac{U_{s}}{U_{p}}, \quad \lambda_{A} \equiv \frac{A_{s}}{A_{p}}, \quad \lambda_{T} \equiv \frac{T_{p}}{T_{s}}=\frac{\rho_{s}}{\rho_{p}}, \quad \lambda_{T^{o}} \equiv \frac{T_{p}^{o}}{T_{s}^{o}},
$$

the following are derived from the conservation equation

$$
\begin{aligned}
& \frac{U_{m}}{U_{p}}=\frac{1+\lambda_{V}^{2} \lambda_{A} \lambda_{T}}{1+\lambda_{V} \lambda_{A} \lambda_{T}}, \\
& \frac{T_{m}^{o}}{T_{p}^{o}}=\frac{1+\lambda_{V} \lambda_{A} \lambda_{T} / \lambda_{T^{o}}}{1+\lambda_{V} \lambda_{A} \lambda_{T}}, \\
& \frac{A_{m}}{A_{p}}=\frac{D_{m}^{2}}{D_{p}^{2}}=\left(1+\lambda_{V} \lambda_{A} \lambda_{T}\right)\left(\frac{\rho_{p}}{\rho_{m}}\right) /\left(\frac{U_{m}}{U_{p}}\right), \\
& \frac{T_{m}}{T_{p}}=\frac{\rho_{p}}{\rho_{m}}=\frac{T_{m}^{o}}{T_{p}^{o}}+\frac{1}{2 c_{p}^{(p)}} \frac{U_{p}^{2}}{T_{p}}\left(\frac{T_{m}^{o}}{T_{p}^{o}}-\frac{c_{p}^{(p)}}{c_{p}^{(m)}} \frac{U_{m}^{2}}{U_{p}^{2}}\right) .
\end{aligned}
$$

The specific heat ratios $\gamma^{(p)}$ and $\gamma^{(s)}$ in the primary and the secondary are evaluated at their respective temperatures, and are used in $c_{p}=\gamma R /(\gamma-1)$ to evaluate the constant pressure specific heat $c_{p}$ in each stream. The mixed jet specific heat ratio is evaluated as $\gamma^{(m)}=\left(\gamma^{(p)} \dot{m}_{p}+\gamma^{(s)} \dot{m}_{s}\right) /\left(\dot{m}_{p}+\dot{m}_{s}\right)$, where $\dot{m}$ is the mass flow rate. The constant pressure specific heat in the mixed jet is evaluated as 


$$
c_{p}^{(m)}=\gamma^{(m)} R /\left(\gamma^{(m)}-1\right)
$$

Similarity features of the mean axial velocity and turbulent kinetic energy in dual stream subsonic jets where examined by Ko and Kwan (Ref. 14). Using appropriate normalization factors defined by Abramovich (Ref. 15) and Eldred et al. (Ref. 16), they were able to identify flow characteristics similar to those in single stream jets within three zones. These consist of the primary/secondary, secondary/ambient, and the fully mixed zones. Accordingly, jet noise for each zone (prior to filtering) is evaluated when the respective velocity $U$, temperature $T$, and diameter $D$ for that zone is supplied as a set of input parameters to a noise module that implements the scaling laws in single-stream jets. The fourth component, that is, the transition jet, lacks an intrinsic similarity, and is treated as a single stream jet at the primary conditions of $U_{p}$ and $T_{p}$, but with an effective diameter $D_{e}$ per equal thrust to that of the dual stream jets, that is

$$
\frac{D_{e}^{2}}{D_{p}^{2}}=1+\lambda_{A} \lambda_{T} \lambda_{V}^{2}
$$

Since the maximum turbulence intensity ratio $u^{\prime} / U_{p}$ in the transition region is much less than the usual 15 to 16 percent measured in the self-similar zones ( $u^{\prime}$ is the rms in velocity fluctuations), an appropriate attenuation factor was deployed within the filter to attenuate the noise accordingly.

\subsection{Spectral Filters}

Nozzle efflux diameters and propulsion inlet conditions for both core and fan streams are supplied to an empirical jet noise model (Ref. 13) that forms a composite spectrum for turbulent mixing noise in dual stream flows

$$
10^{S P L / 10}=10^{(S P L / 10)} \text { primary }+10^{(S P L / 10)_{\text {secondary }}}+10^{(S P L / 10)} \text { transition }+10^{(S P L / 10)} \text { fully-mixed }
$$

Here, $S P L$ denotes the sound pressure level at a third-Octave center frequency, and the summation is carried out after each component noise has been treated with an appropriate high- or low-pass frequency filter. Two low-pass filters are defined as

$$
\begin{aligned}
& F_{1}(\xi)=\left(1+\xi+\frac{\xi^{2}}{25}+\frac{\xi^{3}}{125}+\frac{\xi^{4}}{250}\right) e^{-\xi} \\
& F_{2}(\xi)=\left(1+\xi+\frac{\xi^{2}}{2}+\frac{\xi^{3}}{6}\right) e^{-\xi}
\end{aligned}
$$

where

$$
\xi \equiv m \frac{f}{f^{*}}, \quad m=2
$$

The characteristic frequency $f^{*}$ depends on the velocity to diameter ratio in each component, and $f$ is a third-Octave band center frequency. A high-pass filter is obtained when we subtract a low-pass filter from unity. Noise filtering for each component is briefly described here. 


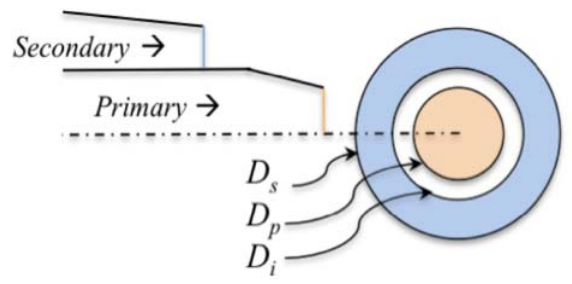

Figure 2.-Dual stream coaxial jets.

\subsubsection{Fully Mixed Region}

This jet is defined as a single stream jet at $U_{m}, T_{m}$ and $D_{m}$ as evaluated from the set of equations (2). The characteristic frequency $f^{*}$ in the fully mixed region additionally depends on diameter ratio $\delta=D_{i} / D_{p}$ (see Fig. 2).

$$
f^{*}=\left(\frac{1}{\delta} \frac{U_{m}}{D_{m}}\right), \quad \text { Filter }(f)=10 \log _{10}\left(F_{1}(\xi)\right)
$$

The above low-pass filter indicates that this component primarily contributes to the low- to midfrequency noise.

\subsubsection{Secondary Jet}

This jet is defined through the secondary jet parameters $U_{s}, T_{s}$, and $T_{m}$, and is expected to contribute to the high frequency noise. The required high-pass filter should be compatible with that in the fully mixed region to accommodate the limiting case when the primary jet becomes relatively weak. In that case, the fully mixed jet and the secondary are identical and the two filters should recover a single jet at the secondary conditions. Parameter $\delta$ best fits the characteristic frequency in the secondary jet as

$$
f^{*}=\delta^{3}\left(\frac{U_{s}}{D_{s}}\right), \quad \text { Filter }(f)=10 \log _{10}\left(1-F_{1}(\xi)\right)
$$

\subsubsection{Transition Jet}

In the absence of an intrinsic similarity within the region, this jet is relatively more ambiguous and requires a more delicate treatment. Under normal flow conditions it is best defined as single stream jet at $U_{p}, T_{p}$ and effective diameter $D_{\text {e }}$ (see Eq. (3)). Due to a reduced turbulence level in the region (compared to the self-similar regions) the noise level is also attenuated by 60 percent - raised to some exponent. A proper exponent (7/2) is derived from physics-based jet noise modeling described by Khavaran et al. (Ref. 17) that scales jet mixing noise versus turbulence intensity. Additionally, a low-pass filter is used at an appropriate characteristic frequency

$$
f^{*}=\frac{U_{p}}{D_{e}}, \quad \text { Filter }(f)=10 \log _{10}(0.60)^{7 / 2}+10 \log _{10}\left(\frac{F_{2}\left(\xi /\left(3 / \lambda_{A}\right)^{3}\right)}{F_{2}\left(\hat{m} /\left(3 / \lambda_{A}\right)^{3}\right)}\right)
$$

where $\hat{m}=\operatorname{Min}(m, \xi)$. The filter, denoted as the second term on the RHS of Equation (10), works more effectively as $\lambda_{A}$ increases. Parameter $\lambda_{A}$ in Equation (10) is replaced with its limits at $\lambda_{A}>3$ or $\lambda_{A}<1$ such 
that $1.0 \leq \lambda_{A} \leq 3.0$. When combined with the high frequency noise from the secondary jet, these two noise components should be required to match the total high frequency noise in a dual stream nozzle.

\subsubsection{Primary Jet}

This jet is defined through parameters $U_{p}, T_{p}$, and $U_{p}$, and is considered subject to a flight speed of $U_{\infty}=U_{s}$. The required high-pass filter is bound by the limiting requirements at $U_{s} \rightarrow 0$.

$$
f^{*}=\left|U_{p}-U_{s}\right| / D_{p}, \quad \text { Filter }(f)=10 \log _{10}\left(1-F_{1}(\xi)\right)
$$

When the secondary jet is relatively insignificant, the fully mixed jet and the primary become identical. The two jets subject to the proposed filters recover the primary jet, as expected.

In the next section, sample calculations are shown using the above model, and new modifications are presented that should help improve the predictions when the bypass stream is the higher velocity and/or temperature jet.

\subsection{Sample Predictions and New Improvements}

Three coannular nozzles shown in Figure 3 were examined by Larson et al. (Ref. 18) as part of a study program directed toward acquisition of acoustic data and measurement of aerodynamic performance of jets with an inverted velocity profile (IVP). The geometries designated as A, B, and C use different diameter ratio $\left(D_{i} / D_{s}\right)$, which is achieved by positioning the secondary throat at different mean radii. The area ratio of the two streams is $\lambda_{A}=1.43$ when the throat area (we are interested in subsonic conditions) is used as the efflux area. Acoustic data is tabulated at a $15 \mathrm{ft}$ arc using a rescaled geometry with a fan diameter of $5 \mathrm{in}$. Secondary outer diameters $D_{s}$, secondary inner diameter $D_{i}$, and the primary diameter $D_{p}$ are:

Geometry A: 5.0, 3.45, 3.02 in.;

Geometry B: 5.0, 3.75, 2.76 in.;

Geometry C: 5.0, 4.15, 2.35 in.

Spectra have also been corrected for atmospheric attenuation and are presented as lossless (i.e., atmospheric attenuation is removed from the measured data).
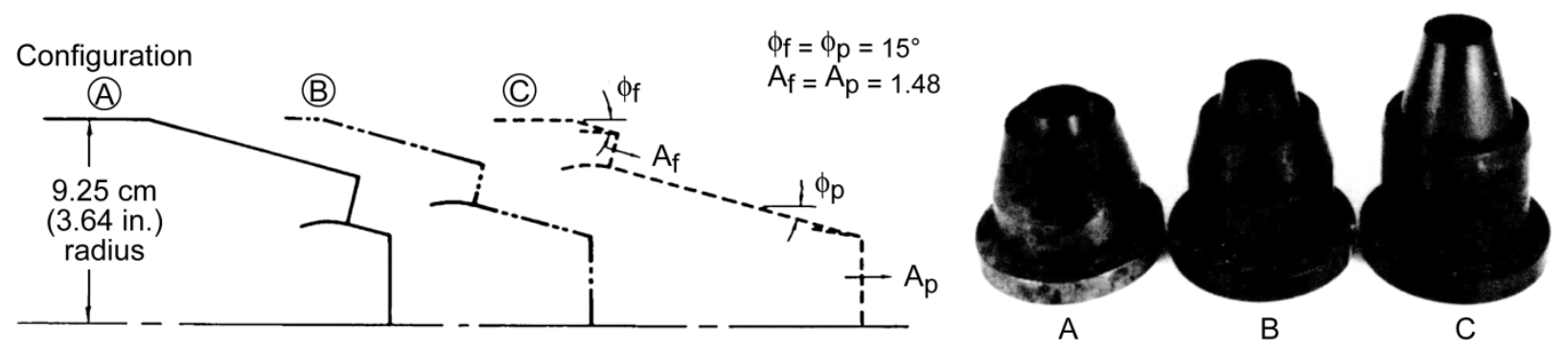

Figure 3.-Coannular nozzle geometries A, B, and C. 
Conditions for the core and fan streams used in the study of Larson et al. are listed in Table 1. The nozzle pressure ratio NPR and the stagnation temperature $T^{o}$ may be used in the usual one-dimensional isentropic relations to evaluate the ideal exit velocity $U$ and static temperature $T$, and subsequently velocity ratio $\lambda_{V}$ and static temperature ratio $\lambda_{T}$. The correct value for the specific heat ratio (a function of static temperature) is found by iteration.

A dual stream jet noise model labeled " $d J e t$ " has been developed that implements the velocity power laws in single stream jets, and forms a composite spectrum in a dual stream flow according to Equation (5). Figures 4, 5, and 6 show sample results for the three conditions of geometry A listed in Table 1. Component noise is color-coded as in Figure 1 to indicate noise emission from various source regions. The first condition, i.e., 8301, corresponds to normal profiles in both velocity and temperature (NVP, NTP). At 8302, the velocity is slightly inverted (IVP, NTP); and finally at 8305 both velocity and temperature are inverted (IVP, ITP). The predictions agree reasonably well with data for conditions 8301 and 8302. However, the aft angle spectrum for condition 8305 does not agree with measurements. The data exhibits a dual peak spectrum (Fig. 6) that is not reflected in the predictions. The noise associated with the fully mixed region is over predicted and the noise associated with the secondary shear layer is under predicted. These observations point to the significance of refraction effects for the inverted profile conditions considered here.

TABLE 1.-COANNULAR NOZZLE TEST CONDITIONS OF LARSON ET AL. (REF. 18)

\begin{tabular}{|l|c|c|c|c|c|c|c|c|c|c|}
\hline Run\# & \multirow{2}{*}{ Geometry } & \multicolumn{3}{|c|}{ Primary (Core) } & \multicolumn{3}{c}{ Secondary (Fan) } & $\lambda_{A}$ & $\lambda_{V}$ & $\lambda_{T}$ \\
\cline { 3 - 9 } & & $N P R$ & $T^{0}-R$ & $U-f p s$ & $N P R$ & $T^{o}-R$ & $U-f p s$ & & & \\
\hline 8301 & A & 1.51 & 1464 & 1421 & 1.30 & 1271 & 1062 & 1.43 & 0.75 & 1.11 \\
\hline 8302 & A & 1.53 & 1465 & 1442 & 1.79 & 1275 & 1548 & 1.43 & 1.07 & 1.20 \\
\hline 8305 & A & 1.51 & 1454 & 1415 & 1.79 & 1980 & 1961 & 1.43 & 1.39 & 0.76 \\
\hline 8201 & B & 1.53 & 1529 & 1476 & 1.29 & 1325 & 1071 & 1.43 & 0.73 & 1.11 \\
\hline 8202 & B & 1.52 & 1535 & 1468 & 1.81 & 1327 & 1595 & 1.43 & 1.09 & 1.22 \\
\hline 8205 & B & 1.51 & 1510 & 1445 & 1.79 & 2034 & 1989 & 1.43 & 1.38 & 0.77 \\
\hline 8401 & C & 1.55 & 1437 & 1448 & 1.29 & 1246 & 1037 & 1.41 & 0.72 & 1.10 \\
\hline 8402 & C & 1.53 & 1434 & 1426 & 1.78 & 1249 & 1525 & 1.41 & 1.07 & 1.20 \\
\hline 8405 & C & 1.53 & 1390 & 1403 & 1.77 & 1936 & 1920 & 1.41 & 1.37 & 0.74 \\
\hline
\end{tabular}
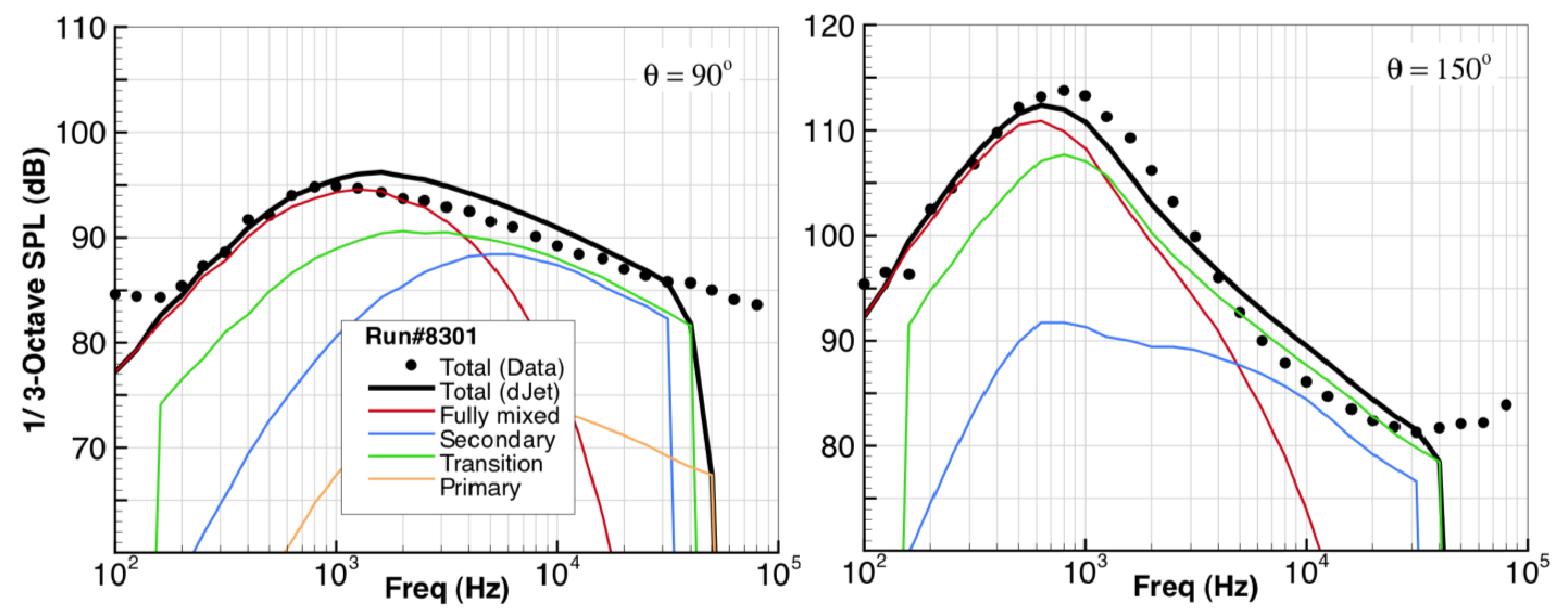

Figure 4.-Prediction and data in a dual stream jet at $90^{\circ}$ and $150^{\circ}$ inlet angles-geometry A Table 1, Run\#8301: $\lambda_{A}=1.43, \lambda_{V}=0.75, \lambda_{T}=1.11$. 

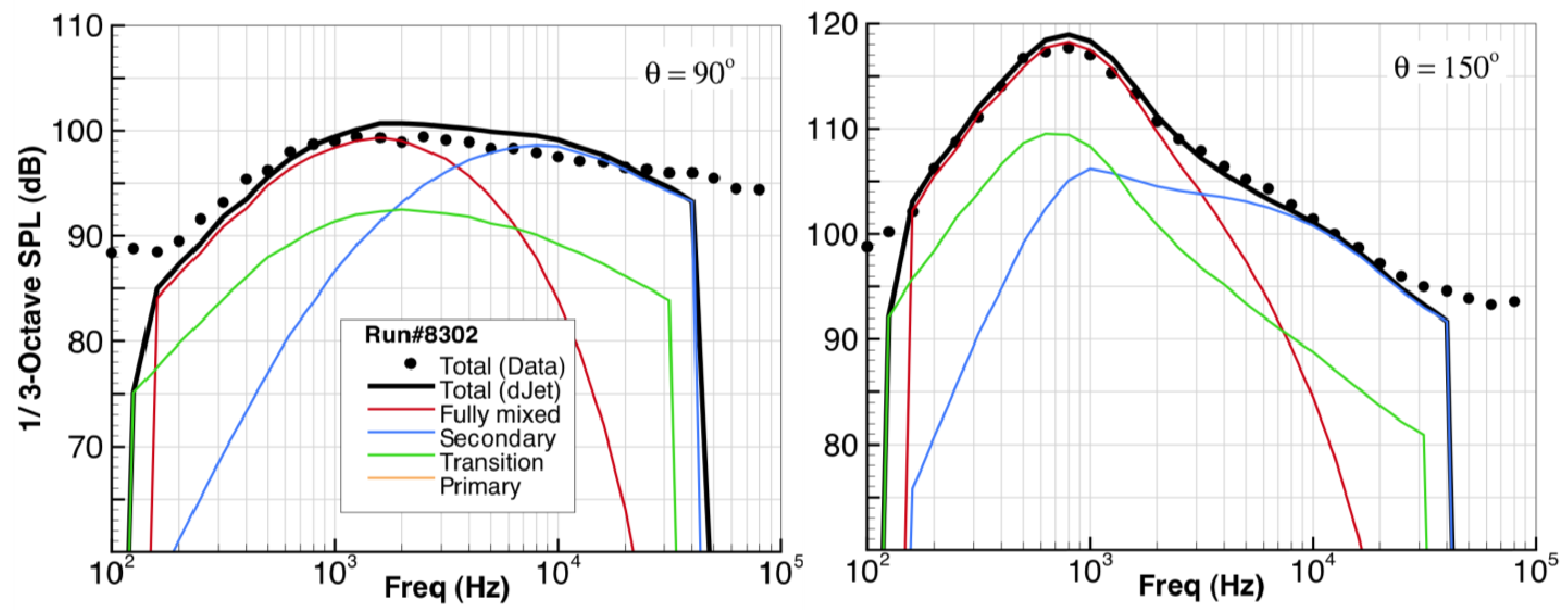

Figure 5.-Prediction and data in a dual stream jet at 900 and 1500 inlet angles-geometry A Table 1, Run\#8302: $\lambda_{A}=1.43, \lambda_{V}=1.07, \lambda_{T}=1.20$.
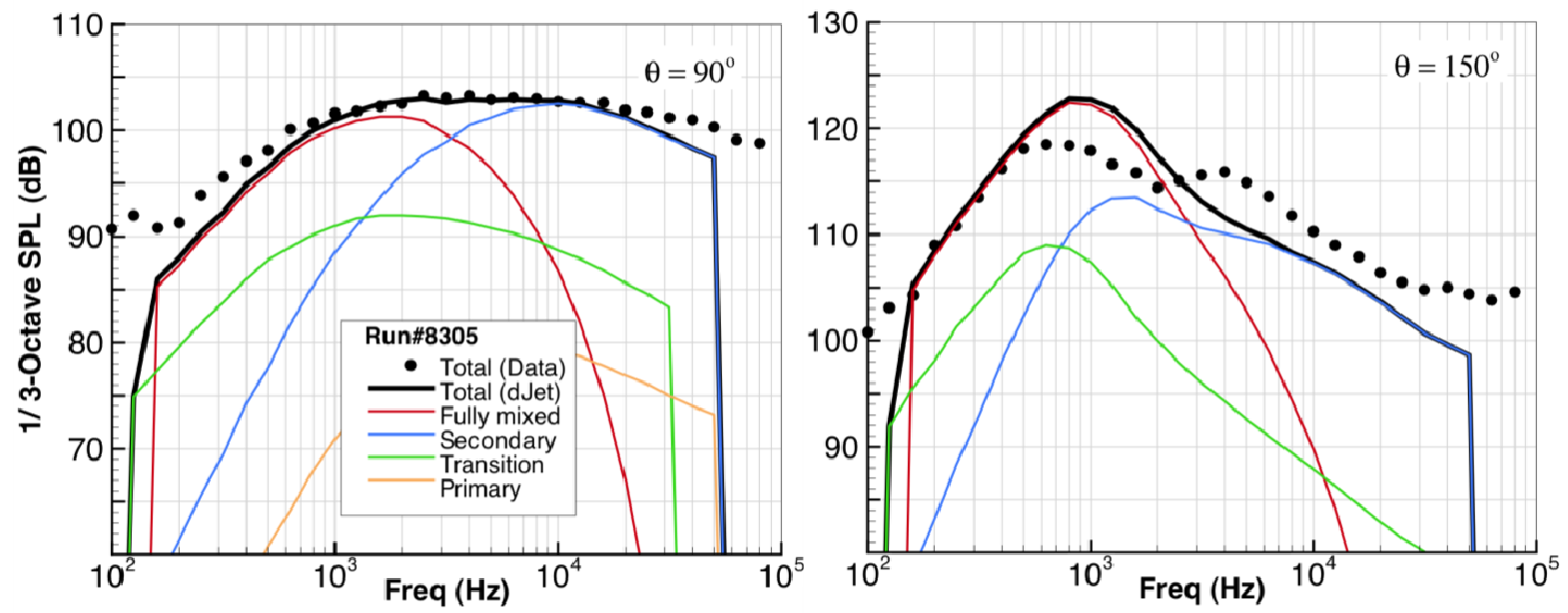

Figure 6.-Prediction and data in a dual stream jet at 900 and 1500 inlet angles-geometry $A$ Table 1, Run\#8305: $\lambda_{A}=1.43, \lambda_{V}=1.39, \lambda_{T}=0.76$.

To shed light on the effect of flow non-uniformities on the refraction of sound we consider a plane vortex sheet separating two uniform flows at conditions 1 and 2, respectively (Fig. 7). A sound wave with a wave normal at angle $\phi_{1}$ refracts at the interface to a new angle $\phi_{2}$. Angle $\phi_{2}$ depends on velocity as well as temperature (sound speed $c$ ) in each medium

$$
\frac{c_{1}}{\operatorname{Sin} \phi_{1}}+V_{1}=\frac{c_{2}}{\operatorname{Sin} \phi_{2}}+V_{2}
$$

Equation (12) is a kinematics statement that requires the wavelength along the interface be equal in both regions. Figure 8 shows the transmission angle $\phi_{2}$ as a function of the incidence angle $\phi_{1}$ when the high-velocity high-temperature medium is in region 1 . Under these conditions, the transmission angle cannot exceed $41.8^{\circ}$ (or $33^{\circ}$ ) when the Mach number $M_{1}$ in region 1 is 0.50 (or 1.0), respectively. Subsequently, a zone of silence is formed in region 2 where no sound wave can penetrate. Conversely, 


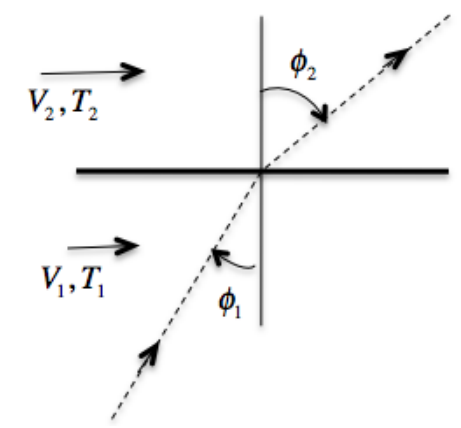

Figure 7.-Refraction of sound at a vortex sheet.

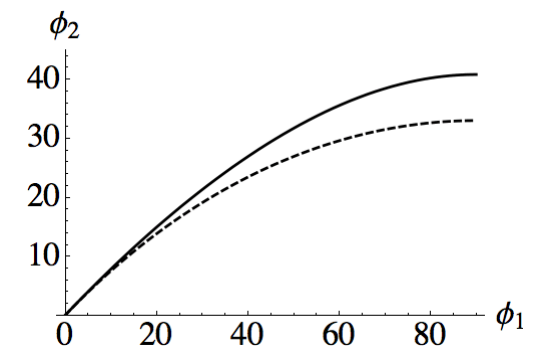

Figure 8.-Refraction at an interface with $V_{2} / V_{1}=0.50$, $T_{1} / T_{2}=1.50$ : (solid line) $M_{1}=0.50 ;$ (dashed line) $M_{1}=1.0$.

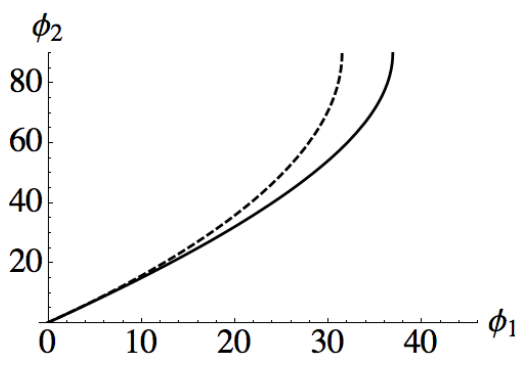

Figure 9.-Refraction at an interface with $V_{2} / V_{1}=1.50$, $T_{1} / T_{2}=0.50$ : (solid line) $M_{1}=0.50$; (dashed line) $M_{1}=1.0$.

when the high-velocity high-temperature medium is located in region 2, certain incidence angles $\phi_{1}$ fail to penetrate into region 2. For example, under the conditions of Figure 9, when $M_{1}=0.50$ (or 1.0), waves with incidence angles exceeding some critical value $\phi_{1 c}=37^{\circ}$ (or $\left.31.5^{\circ}\right)$ do not reach into region 2 . These conditions lead to a total reflection, and sound pressure in region 2 decays exponentially with distance from the boundary.

Using the examples shown here, it is readily concluded that the high-frequency jet noise emitted from the initial mixing region (see Fig. 1) has a higher likelihood of reaching small aft angles in dual stream jets with IVP/ITP as compared to NVP/NTP. In fact, in the latter case, a cone of relative silence is formed near the downstream jet axis. In the fully mixed region, noise emitted at angles $\phi_{1}>\phi_{1 c}$ under IVP/ITP conditions, goes through a total reflection and decays with distance from the jet; hence low frequency noise at small aft angles is expected to have a relatively lower amplitude compared to that in jets with NVP/NTP conditions.

Considering these observations, several modifications are introduced in the model proposed earlier that adjust the amplitude as well as characteristics frequency of a number of noise components. These adjustments are necessary due to the fact that the scaling laws of jet noise in single stream jets were based on noise measurements under NVP/NTP conditions. 


\subsection{Model Modifications}

The parametric changes proposed here are intended to improve the dual stream jet noise prediction model of Section 3 under inverted velocity $\left(\lambda_{V}>1\right)$ and/or inverted temperature conditions (IVP/ITP).

\subsection{Secondary Jet}

The adjustments made in the secondary/ambient mixing region are intended to modify both noise amplitude and its characteristics frequency $f^{*}$. As stated before, this component noise is defined in terms of a single stream jet at the conditions of the secondary jet $U_{s}, T_{s}$ (here we use $T_{\mathrm{s}}$ as normalized with respect to the ambient temperature). The jet diameter $D_{s}$ is now modified as $\hat{D}_{s}$

$$
\hat{D}_{s}=D_{s} \times \mid \begin{array}{lr}
\lambda_{A} /\left(2 T_{s}^{0.5}\right), & \theta \leq 125^{\circ} \\
\lambda_{A} /\left(2 T_{s}\right), & 125^{\circ}<\theta \leq 135^{\circ} \\
\lambda_{A} /\left(1.5 T_{s}\right), & 135^{\circ}<\theta \leq 145^{\circ} \\
F\left(\lambda_{A}\right) / T_{s}, & 145^{\circ}<\theta
\end{array}
$$

The adjustment factor at small aft angles $\theta>145^{\circ}$ becomes a function of the area ratio $\lambda_{A}$, shown as $\mathrm{F}\left(\lambda_{A}\right)$ in Figure 10. When $\lambda_{A}<0.50$ this parameter is set equal to 0.35 .

The modifications in the filter are as follows:

(a) The filter functions $F_{1}(\xi)$ in the secondary now consists of an additional parameter $\sqrt{T_{s}}$ in the exponent and is denoted as $\hat{F}_{1}\left(\xi, T_{s}\right)$

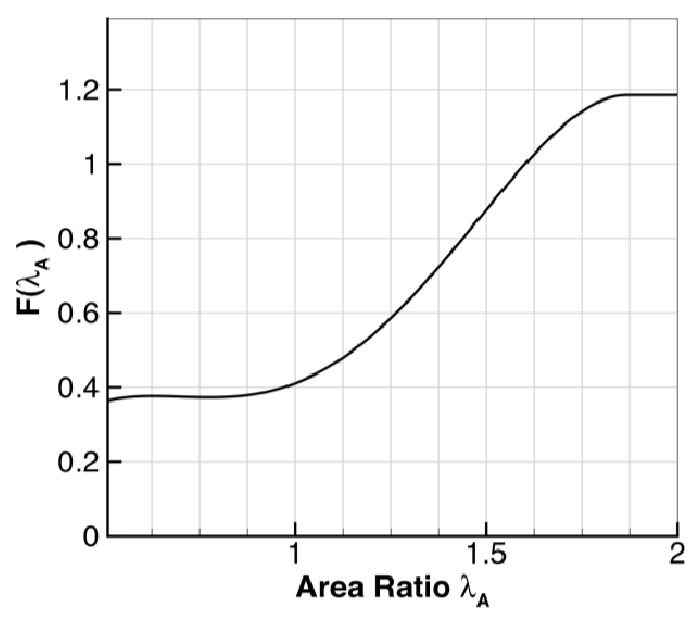

Figure 10.-Diameter adjustment factor for the fully mixed jet as defined in Equation (13). 


$$
\hat{F}_{1}\left(\xi, T_{s}\right)=\left(1+\xi+\frac{\xi^{2}}{25}+\frac{\xi^{3}}{125}+\frac{\xi^{4}}{250}\right) e^{-\xi \sqrt{T_{s}}}
$$

where $\xi=2 f / f^{*}$ as defined earlier.

(b) The characteristic frequency is modified as

$$
f^{*}=\left(\frac{U_{s}}{D_{s}}\right) \times \mid \begin{array}{cc}
T_{s}^{0.25}, & \theta \leq 130^{\circ} \\
\delta^{3} T_{s}^{0.25}, & 130^{\circ}<\theta \leq 140^{\circ} \\
\delta^{3} T_{s}^{-0.75}, & 140^{\circ}<\theta
\end{array}
$$

\subsection{Fully Mixed Jet}

In jets with an inverted velocity profile $\left(\lambda_{V}>1\right)$, the fully mixed jet is defined by values of $U_{m}, T_{m}$ and $\hat{D}_{m}$, where $\hat{D}_{m}=\sqrt{\delta} D_{m}$, and $D_{m}$ is calculated from Equation (2). Additionally, an adjustment factor $\alpha_{F m x}\left(\lambda_{V}\right)$ is designed to attenuate the amplitude of this noise component through its filter

$$
\text { Filter }(f)=10 \log _{10}\left(F_{1}(\xi)\right)-\alpha_{F m x}
$$

The attenuation in the fully mixed noise will be compensated by an increase in the amplitude of the transition noise through factor $\alpha_{T m}\left(\lambda_{V}\right)$ as discussed shortly. The functional forms of these two parameters are shown in Figure 11.

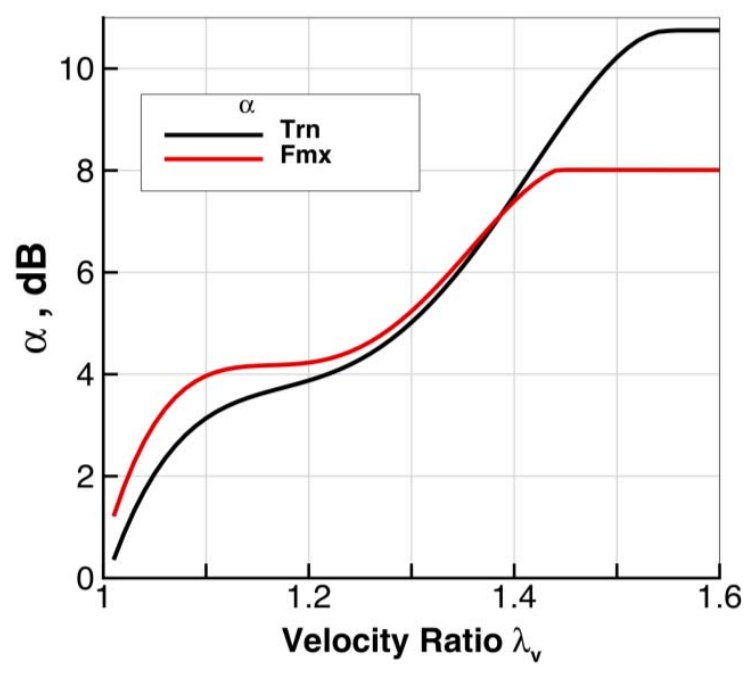

Figure 11.-Amplitude adjustment parameter in the fully mixed and transition jets. 


\subsection{Transition Jet}

The transition component of jet noise in dual stream jets with an inverted velocity profile is evaluated as before through parameters $U_{p}, T_{p}$, and $D_{\mathrm{e}}$. The new modification consists of an adjustment factor $+\alpha_{T m}\left(\lambda_{V}\right)$ in the filter expression Equation (10). Thus, as the velocity ratio is increased, there is a tradeoff of noise between these two latter noise components.

\subsection{Primary Jet}

The modeling of this noise component remains unaltered.

It should be noted that when the bypass stream dominates the core flow in terms of its total mass and jet speed (typically $\lambda_{V}>1.70$, and assuming that the bypass ratio BPR $=\lambda_{V} \lambda_{A} \lambda_{T}$ is not small) the secondary and the fully mixed regions, in combination, dominate a composite spectrum. The spectrum is then expected to look like that in a single stream jet—subsequently the dual peak spectral character should disappear.

\subsection{Sample Results Using Modified Model}

The dual stream jet noise methodology " $d J e t$ " is applied to jet configurations listed in Table 1, and predictions are examined with emphasis on unconventional operating conditions of IVP/ITP. As before, the one-third Octave band spectra are shown on a $15 \mathrm{ft}$ arc at $90^{\circ}$ and $150^{\circ}$. Figure 12 should be compared with Figures 5 and 6 shown earlier. The high frequency amplitude (i.e., the secondary stream component) is enhanced under the conditions of the inverted velocity profile. At the same time, a shift in the spectral peak of this noise component brings about a second peak at the higher velocity ratio of $\lambda_{V}=1.39$. Similar features are observed in geometry B (Fig. 13) and geometry C (Figure 14). At a velocity ratio of 1.09, the second peak is gradually forming and a significant increase in the high frequency noise is noticeable relative to the lower velocity ratio of 0.76 . The low frequency noise is shaped primarily by the fully mixed and the transition components of jet noise. A gradual transition of the acoustic energy from the former source to the latter takes place concurrently with the development of the second peak, as seen in Figures 12,13 , and 14 . This indicates that the transition jet could steadily advance into the fully mixed region and eventually the two zones become one. Under such conditions, the dual spectral feature at aft angles is expected to disappear as the high frequency noise from the combined transition and fully mixed zones overwhelm the contribution from the secondary source. 

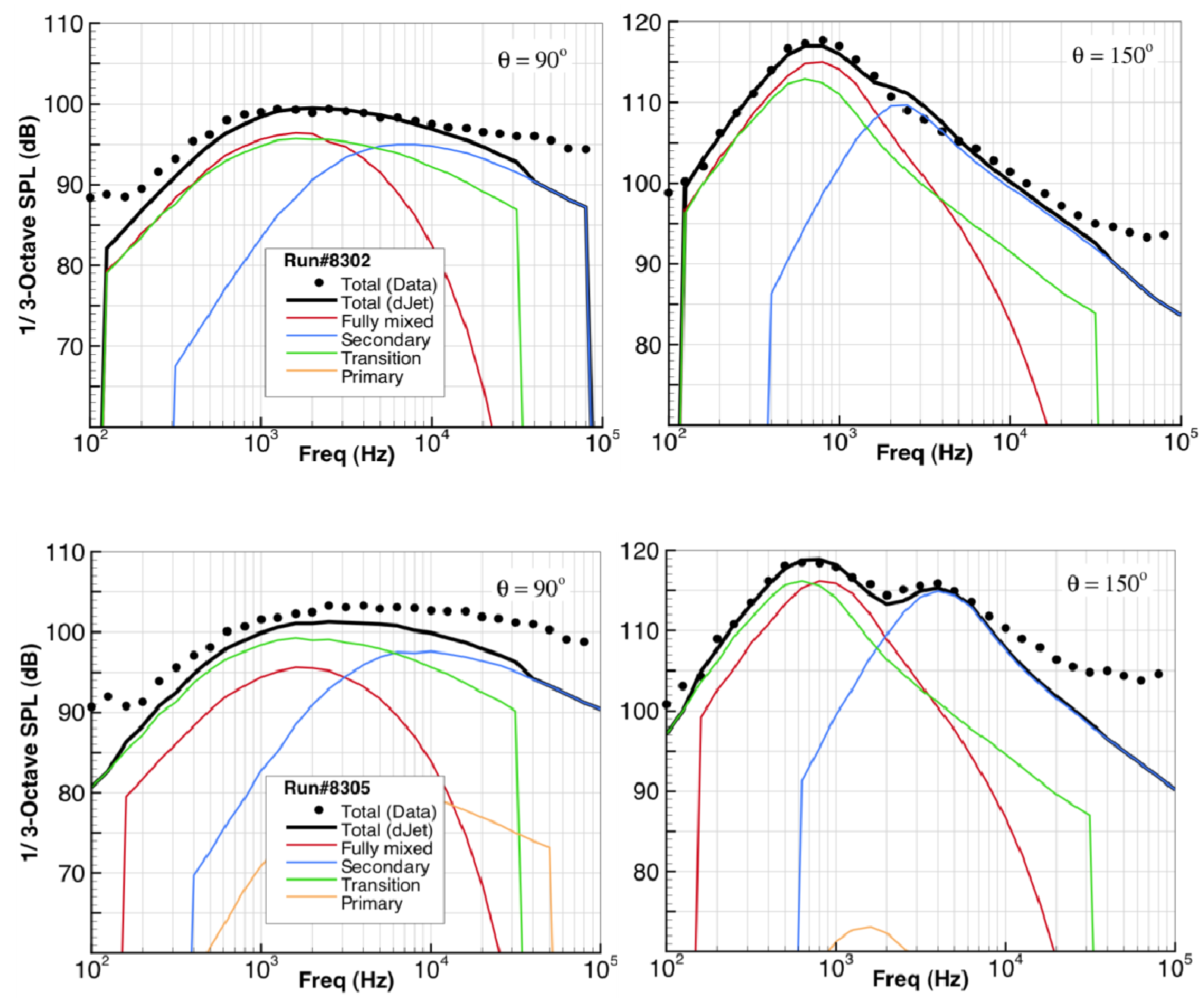

Figure 12.-Data and predictions at $90^{\circ}$ and $150^{\circ}$ inlet angles in dual stream jet geometry $A$ of Table 1. Top row Run\#8302: $\lambda_{A}=1.43, \lambda_{V}=1.07, \lambda_{T}=1.20$; bottom row Run\#8305: $\lambda_{A}=1.43, \lambda_{V}=1.39, \lambda_{T}=0.76$. 

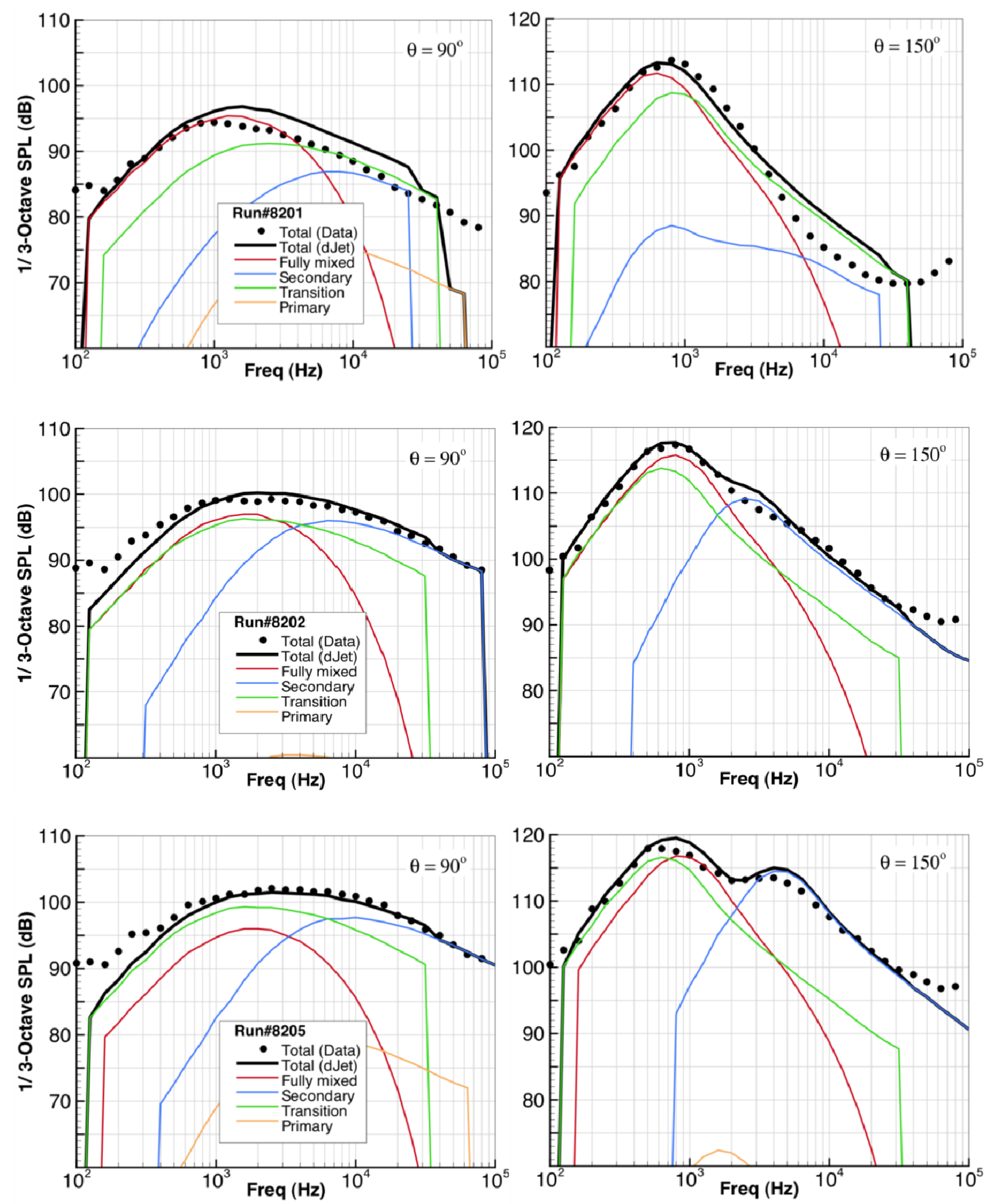

Figure 13.-Data and predictions at $90^{\circ}$ and $150^{\circ}$ inlet angles in dual stream jet geometry B of Table 1. Top row: Run\#8201: $\lambda_{A}=1.43, \lambda_{V}=0.73, \lambda_{T}=1.11$; middle row: Run\#8202: $\lambda_{A}=1.43, \lambda_{V}=1.09, \lambda_{T}=1.22$; bottom row: Run\#8205: $\lambda_{A}=1.43, \lambda_{V}=1.38, \lambda_{T}=0.77$. 

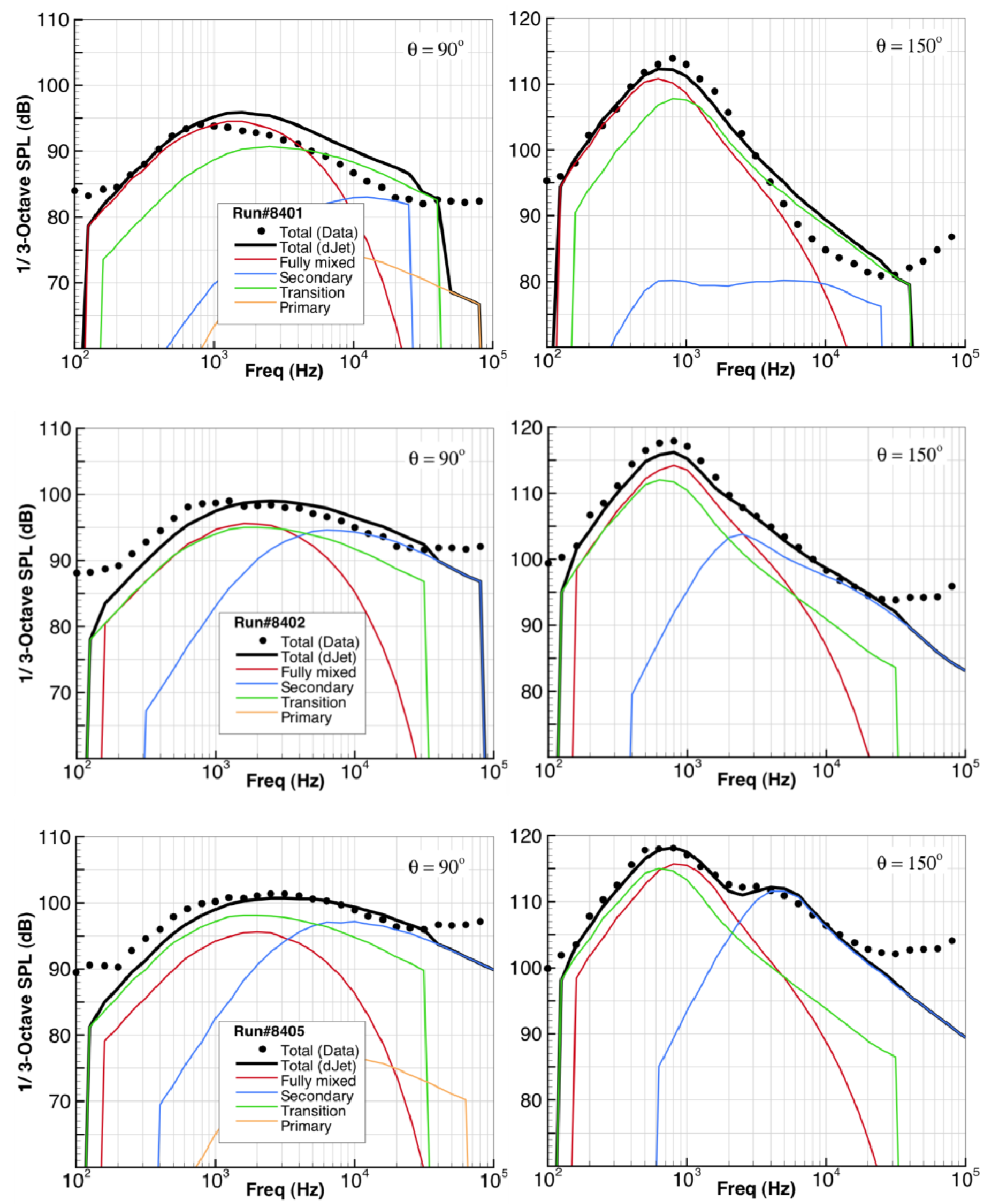

Figure 14.-Data and predictions at $90^{\circ}$ and $150^{\circ}$ inlet angles in dual stream jet geometry $C$ of Table 1. Top row: Run\#8401: $\lambda_{A}=1.41, \lambda_{V}=0.72, \lambda_{T}=1.10$; middle row: Run\#8402: $\lambda_{A}=1.41, \lambda_{V}=1.07, \lambda_{T}=1.20$; bottom row: Run\#8405: $\lambda_{A}=1.41, \lambda_{V}=1.37, \lambda_{T}=0.74$. 
To further validate the spectral features discussed earlier, we now examine a second set of dual stream jet noise data as reported by Kozlowski et al. (Refs. 19 and 20). A number of shock-free test conditions at two area ratios of 0.76 and 1.22, designated as configurations 2 and 14, are listed in Table 2 . Geometry details for each configuration may be found in Reference 19. The primary nozzle in each configuration is a convergent-divergent nozzle with an exit to throat area ratio of 1.10. An extensive test matrix that includes both subsonic and supersonic pressure ratios for the two streams is tabulated in Reference 20. Since we are only interested in the subsonic conditions, the throat dimension is used as the nozzle exit plane. Diameters of the secondary and primary nozzles at their respective efflux planes are listed in the order of $D_{\mathrm{s}}, D_{\mathrm{i}}$, and $D_{\mathrm{p}}$

Configuration 2: 5.0, 3.93, 3.54 in., Configuration 14: 5.0, 3.58, 3.16 in.

The test points shown in Table 2 represent a combination of normal and inverted velocity and/or temperature profiles. Lossless acoustic data are reported on an arc at 36 fan diameters $(15 \mathrm{ft})$ for all configurations. The dual stream jet noise model " $d J e t$ " is implemented as before, and the component spectra are presented at two inlet angles of $90^{\circ}$ and $150^{\circ}$.

Figures 15 through 23 show how these predictions compare against data. Figures 15, 16, 17, and 18 relate to configuration 2 , that is, area ratio of 0.76 . The velocity ratio is increased incrementally from a normal velocity profile at $\lambda_{V}=0.59$ to an inverted velocity profile at $\lambda_{V}=1.60$. Simultaneously, the temperature ratio is decreased from a normal temperature profile at $\lambda_{T}=1.72$ to an inverted temperature profile $\lambda_{T}=0.57$. Model predictions show a steady increase in high frequency noise in the secondary. A shift in the peak amplitude of this noise component brings about a second spectral peak. Figure 16 shows that the second peak is nearly about to form. Low frequency noise from the combined transition and fully mixed components develop into to the first peak at aft angles, and a single peak along the jet sideline angles. The two sources interchange strength as the velocity ratio is increased.

Figures 19, 20, 21, 22, and 23 are applicable to configuration 14, that is, area ratio of 1.22. Here the velocity ratio is increased incrementally from 0.74 to 1.57 for a selection of temperatures that include both NTP and ITP. The trend is similar to the sequence of the previous figures. At the conditions of $\lambda_{V}=1.07$ and 1.08 a second peak is barely visible in the predictions of Figures 20 and 21, which is missing from the measurements. As we will see shortly, the true exit velocities in the core and bypass streams of a dual stream jet may be slightly less than the ideal values as a result of losses associated with the discharge coefficient in each nozzle. This could have an impact on the prediction of the second peak at conditions that may be considered as a borderline between NVP and IVP.

TABLE 2.-COANNULAR NOZZLE TEST CONDITIONS OF KOZLOWSKI ET AL. (REF. 20)

\begin{tabular}{|c|c|c|c|c|c|c|c|c|c|c|}
\hline \multirow[t]{2}{*}{ Run\# } & \multirow[t]{2}{*}{ Config. } & \multicolumn{3}{|c|}{ Primary (core) } & \multicolumn{3}{|c|}{ Secondary (fan) } & \multirow[t]{2}{*}{$\lambda_{A}$} & \multirow[t]{2}{*}{$\lambda_{V}$} & \multirow[t]{2}{*}{$\lambda_{T}$} \\
\hline & & $N P R$ & $T^{o}-R$ & $U-f p s$ & NPR & $T^{o}-R$ & $U-f p s$ & & & \\
\hline PWK006.04 & 2 & 1.52 & 1246 & 1333 & 1.31 & 695 & 788 & 0.76 & 0.59 & 1.72 \\
\hline PWK005.02 & 2 & 1.52 & 687 & 965 & 1.78 & 680 & 1115 & 0.76 & 1.15 & 1.06 \\
\hline PWK034.04 & 2 & 1.55 & 1255 & 1347 & 1.80 & 1949 & 1953 & 0.76 & 1.45 & 0.66 \\
\hline PWK026.03 & 2 & 1.52 & 697 & 973 & 1.80 & 1270 & 1552 & 0.76 & 1.60 & 0.57 \\
\hline PWK418.04 & 14 & 1.53 & 1453 & 1436 & 1.30 & 1275 & 1065 & 1.22 & 0.74 & 1.09 \\
\hline PWK418.03 & 14 & 1.54 & 1464 & 1452 & 1.82 & 1275 & 1557 & 1.22 & 1.07 & 1.22 \\
\hline PWK428.03 & 14 & 1.53 & 701 & 982 & 1.30 & 1264 & 1060 & 1.22 & 1.08 & 0.53 \\
\hline PWK417.02 & 14 & 1.53 & 1454 & 1437 & 1.82 & 1948 & 1969 & 1.22 & 1.37 & 0.78 \\
\hline PWK428.02 & 14 & 1.52 & 714 & 984 & 1.80 & 1264 & 1548 & 1.22 & 1.57 & 0.59 \\
\hline PWK036.03 & 2 & 1.52 & 1450 & 1404 & 1.81 & 1615 & 1745 & 0.76 & 1.24 & 0.94 \\
\hline
\end{tabular}



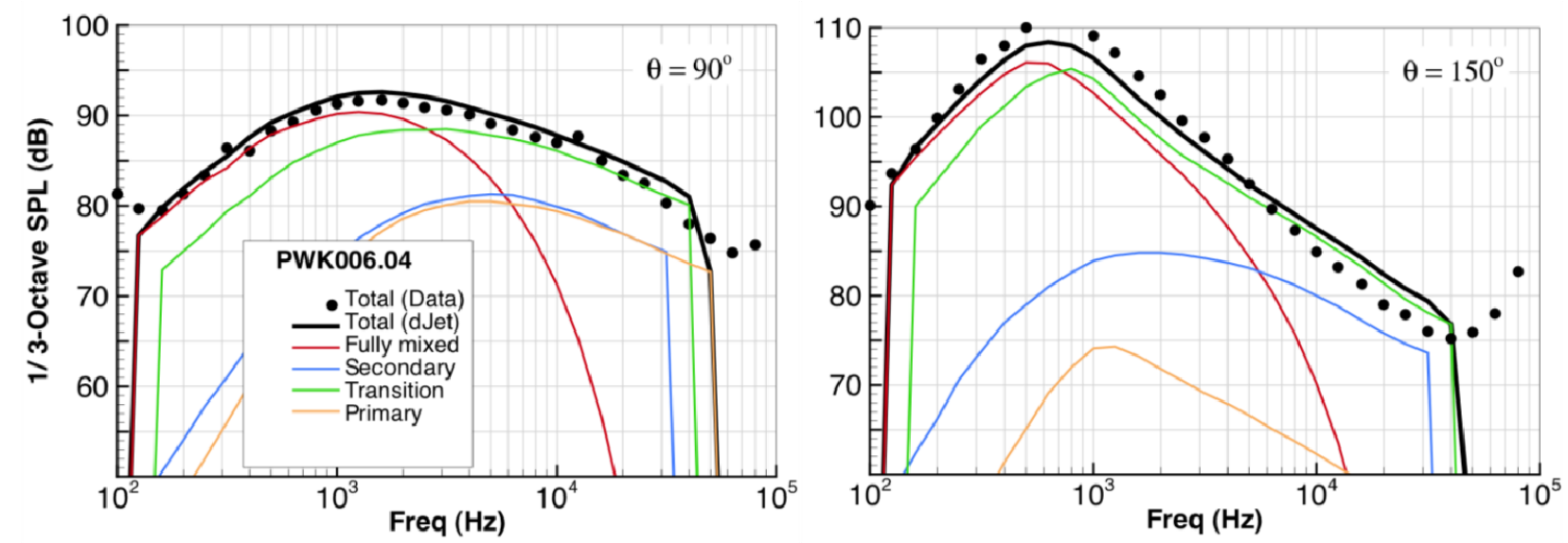

Figure 15.-Data and predictions at $90^{\circ}$ and $150^{\circ}$ inlet angles in dual stream jet configuration 2 of Table 2, Run\# PWK006.04: $\lambda_{A}=0.76, \lambda_{V}=0.59, \lambda_{T}=1.72$.
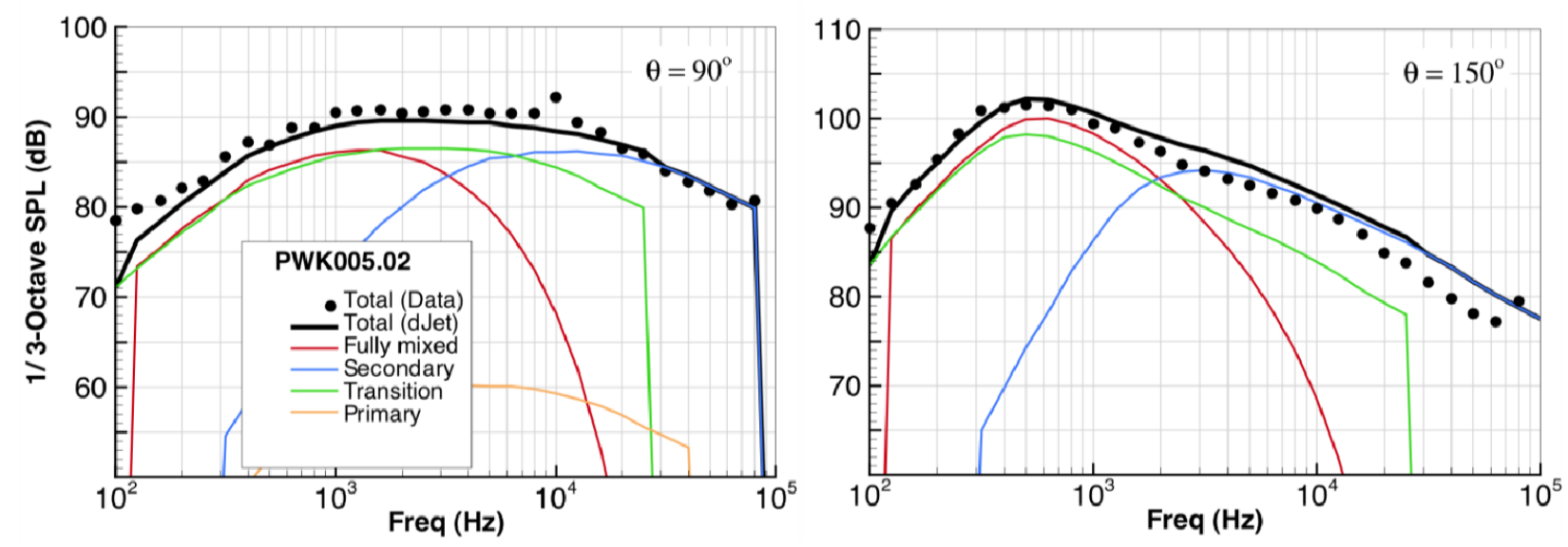

Figure 16.-Data and predictions at $90^{\circ}$ and $150^{\circ}$ inlet angles in dual stream jet configuration 2 of Table 2, Run\# PWK005.02: $\lambda_{A}=0.76, \lambda_{V}=1.15, \lambda_{T}=1.06$.
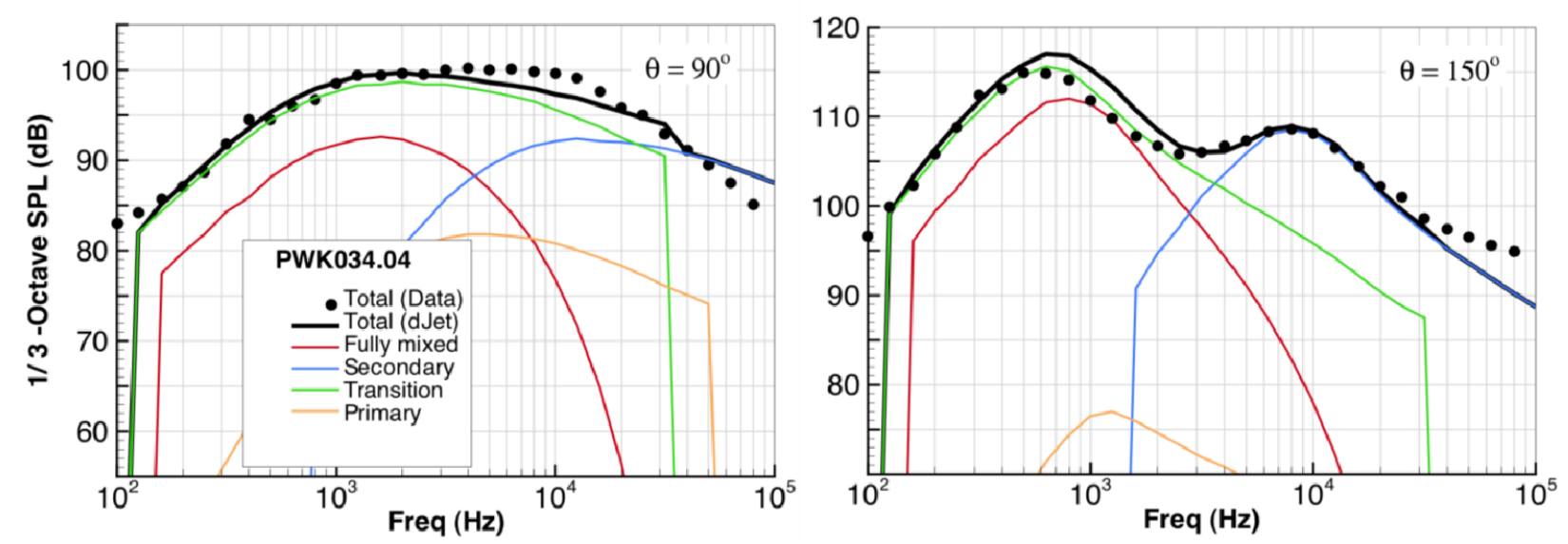

Figure 17.-Data and predictions at $90^{\circ}$ and $150^{\circ}$ inlet angles in dual stream jet configuration 2 of Table 2, Run\# PWK034.04: $\lambda_{A}=0.76, \lambda_{V}=1.45, \lambda_{T}=0.66$. 

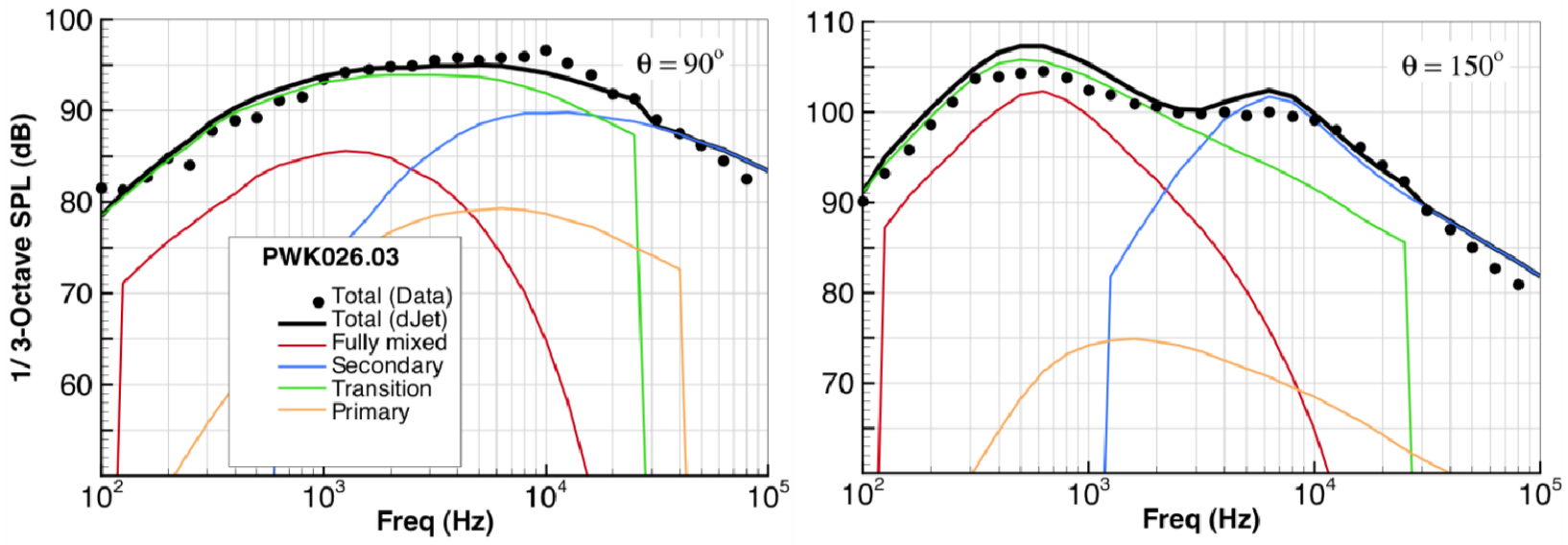

Figure 18.-Data and predictions at $90^{\circ}$ and $150^{\circ}$ inlet angles in dual stream jet configuration 2 of Table 2, Run\# PWK026.03: $\lambda_{A}=0.76, \lambda_{V}=1.60, \lambda_{T}=0.57$.
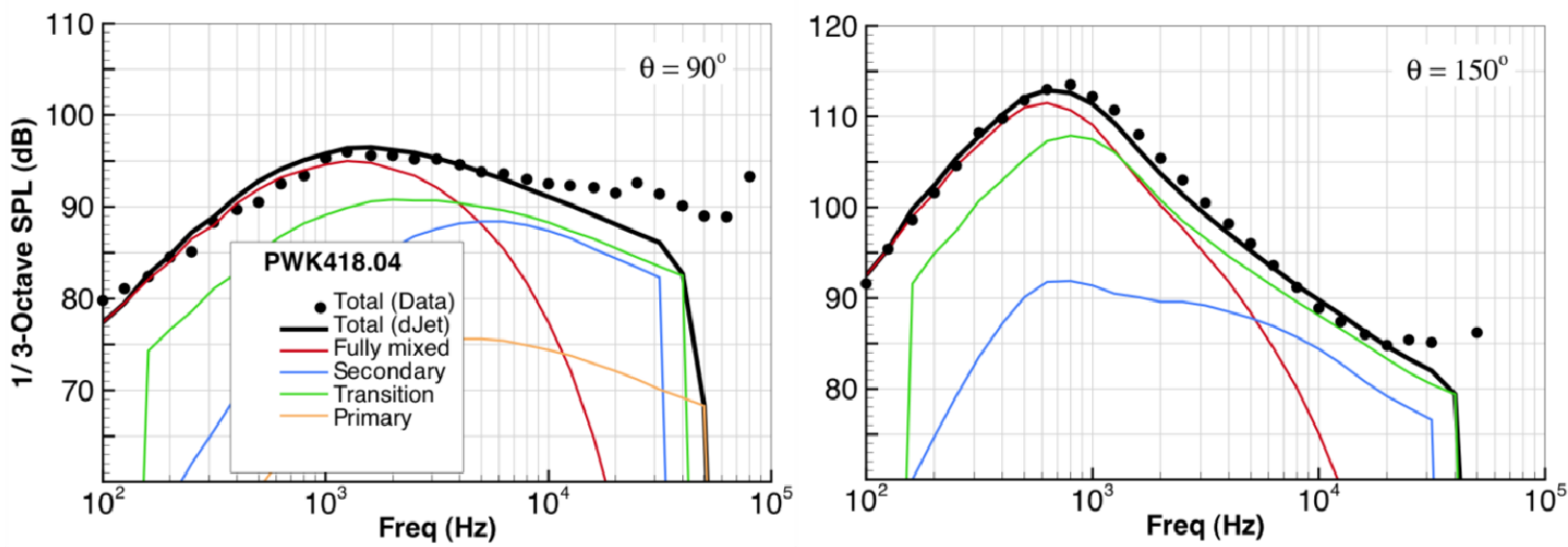

Figure 19.-Data and predictions at $90^{\circ}$ and $150^{\circ}$ inlet angles in dual stream jet configuration 14 of Table 2 , Run\# PWK418.04: $\lambda_{A}=1.22, \lambda_{V}=0.74, \lambda_{T}=1.09$.
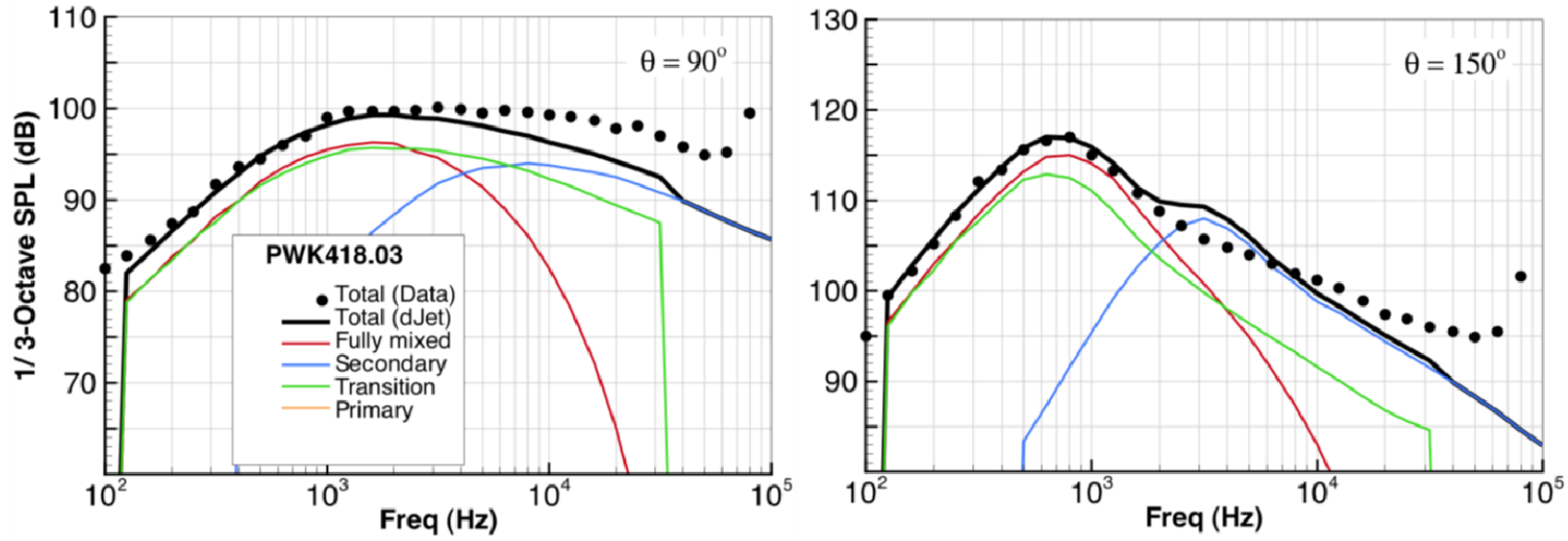

Figure 20.-Data and predictions at $90^{\circ}$ and $150^{\circ}$ inlet angles in dual stream jet configuration 14 of Table 2, Run\# PWK418.03: $\lambda_{A}=1.22, \lambda_{V}=1.07, \lambda_{T}=1.22$. 

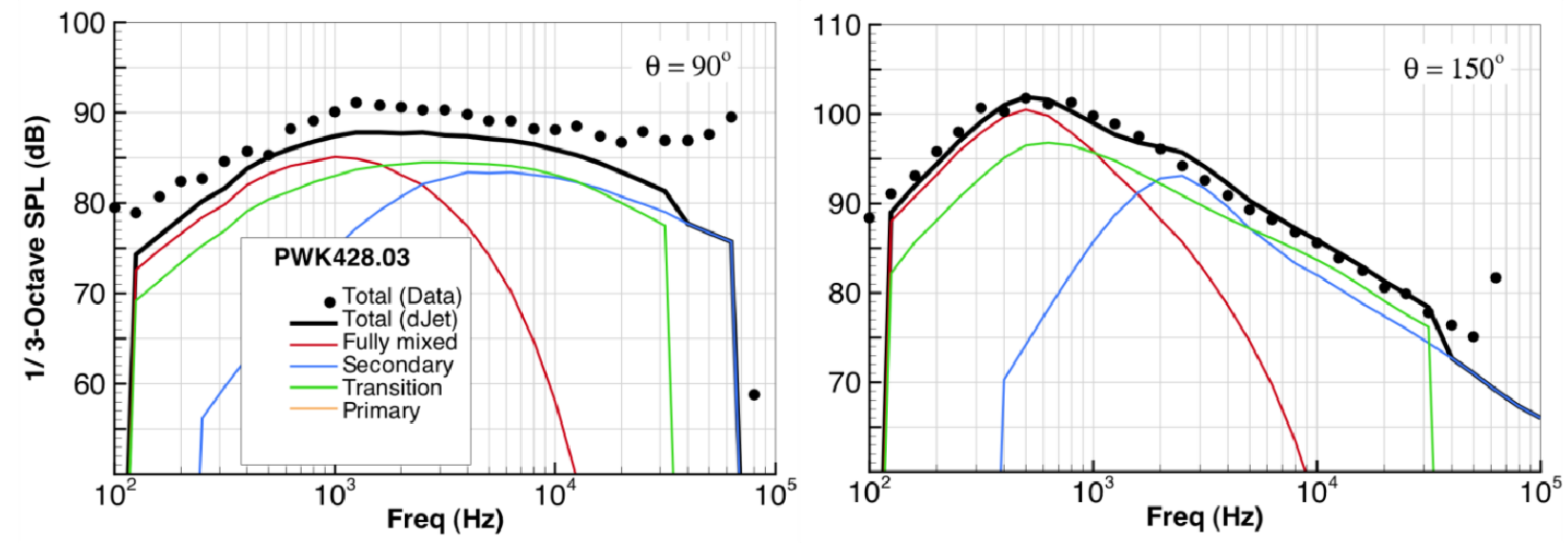

Figure 21.-Data and predictions at $90^{\circ}$ and $150^{\circ}$ inlet angles in dual stream jet configuration 14 of Table 2, Run\# PWK428.03: $\lambda_{A}=1.22, \lambda_{V}=1.08, \lambda_{T}=0.53$.
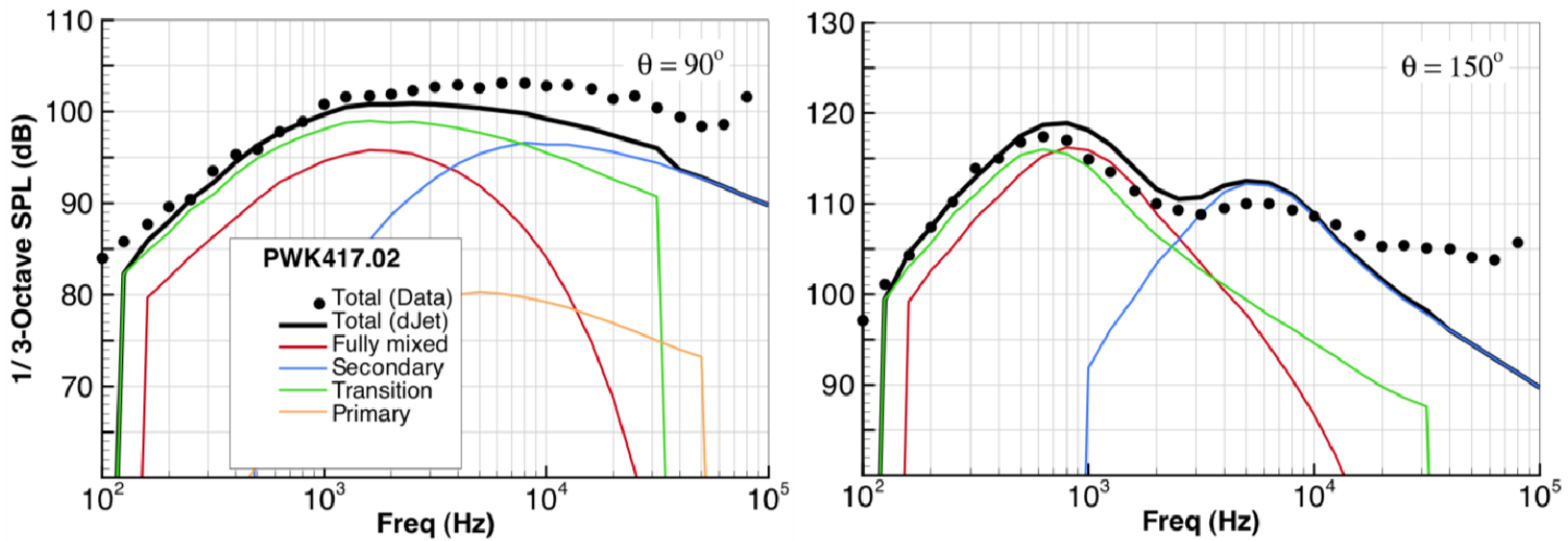

Figure 22.-Data and predictions at $90^{\circ}$ and $150^{\circ}$ inlet angles in dual stream jet configuration 14 of Table 2, Run\# PWK417.02: $\lambda_{A}=1.22, \lambda_{V}=1.37, \lambda_{T}=0.78$.
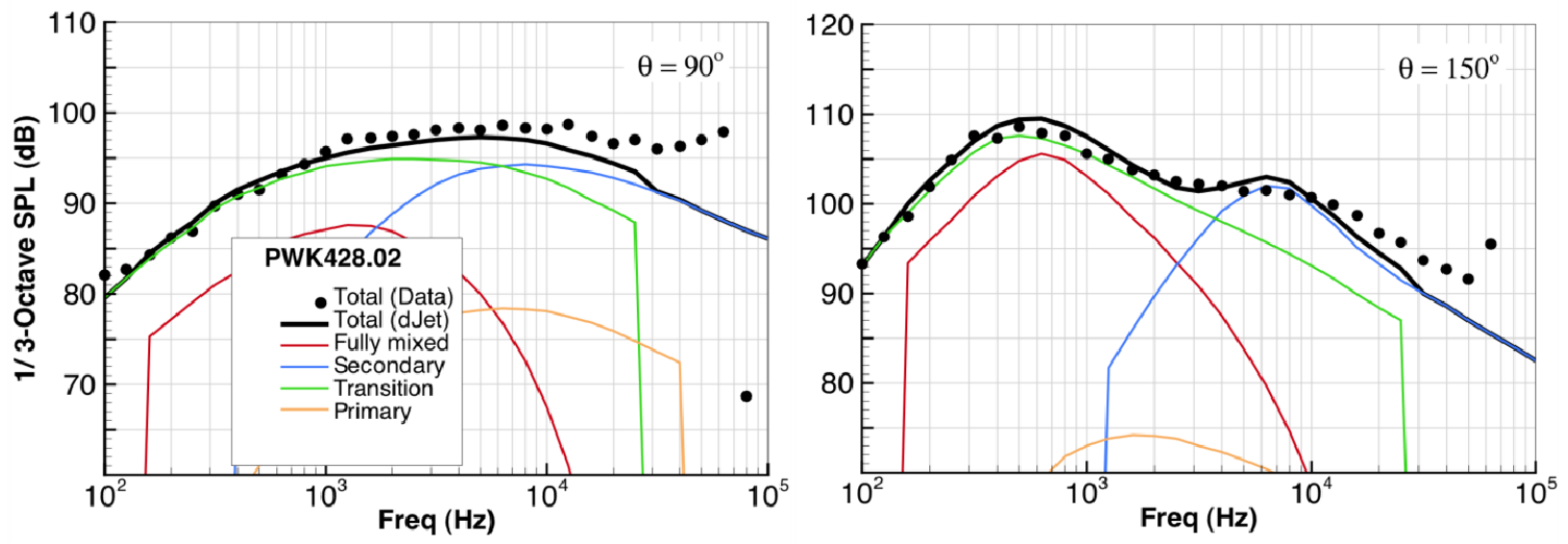

Figure 23.-Data and predictions at $90^{\circ}$ and $150^{\circ}$ inlet angles in dual stream jet configuration 14 of Table 2, Run\# PWK428.02: $\lambda_{A}=1.22, \lambda_{V}=1.57, \lambda_{T}=0.59$. 

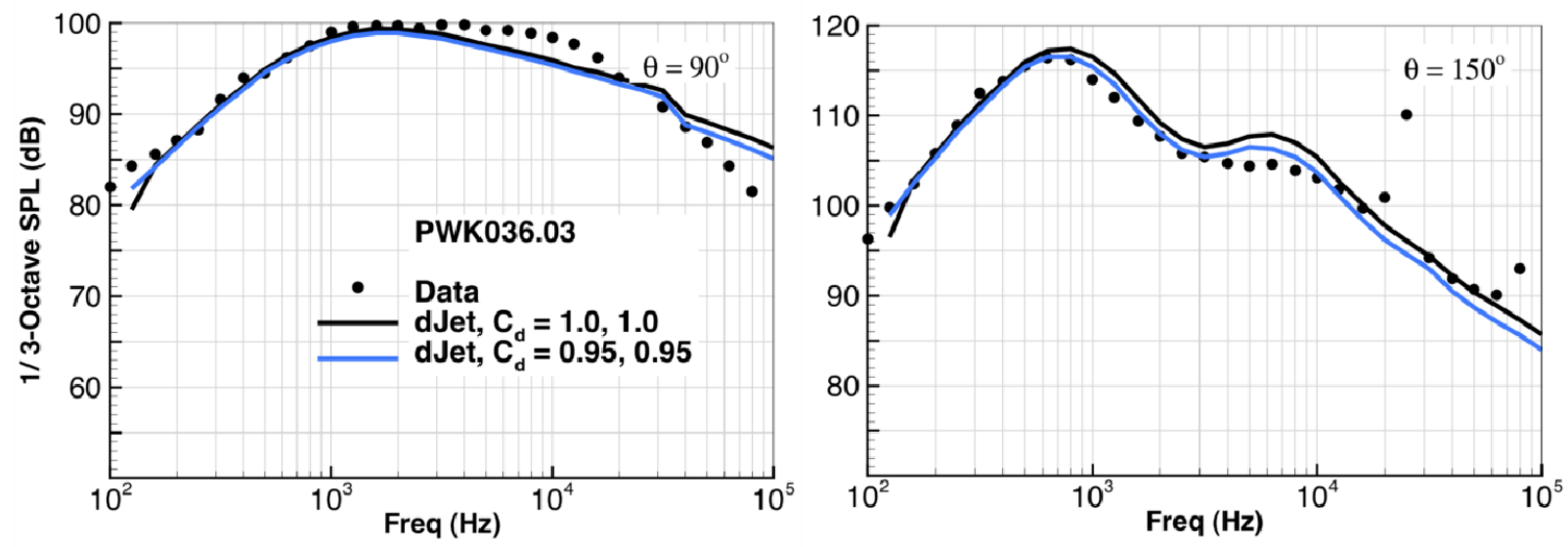

Figure 24.-The effect of the discharge coefficient on noise at $90^{\circ}$ and $150^{\circ}$ inlet angles in dual stream jet configuration 2 of Table 2, Run\# PWK036.03: $\lambda_{A}=0.76, \lambda_{V}=1.24, \lambda_{T}=0.94$.

As indicated earlier, the ideal efflux velocities for core and fan streams are evaluated based on the one-dimensional isentropic flow relations. In practice the true jet velocity is somewhat less than the ideal one, and depends on the nozzle discharge coefficient. Appendix A describes the relationship between the ideal velocity and the true velocity once the discharge coefficient for a nozzle is specified. To examine the effect of the discharge coefficient on noise, we consider the final set point from Table 2 at Run\#PWK036.03. The ideal velocities for the core and fan streams are evaluated as 1404 and $1745 \mathrm{fps}$, respectively. We choose a set of discharge coefficients of 0.95 for both core and fan nozzles. The true velocities are evaluated as 1346 and $1678 \mathrm{fps}$, respectively. Under such conditions, slightly less noise should be expected relative to that at the ideal conditions. Figure 22 shows the effect of the discharge coefficient on noise. The new velocity ratio $\left(\lambda_{V}=1.246\right)$ still remains close to the value listed in the Table, however it is not uncommon for the velocity ratio to change relative to the ideal conditions.

\subsection{Summary and Future Work}

A semi-empirical model has been proposed to predict turbulent mixing noise in dual-stream jets. The model applies a four-component composite spectrum for such flows, where each component contribution is founded on velocity scaling laws for single stream jets. Examination of acoustic data in jets under unconventional conditions of inverted velocity/temperature profiles required a number of modifications in the model. Refraction of sound at a plane vortex sheet was used to shed light on some of the observed dual spectral features of jet noise at small aft angles. Subsequently, adjustments were proposed that modify a number of parameters such as diameter, characteristic frequency, and the spectral filter in the secondary mixing region and the fully mixed region. In addition, the transition and fully mixed regions required amplitude adjustments as a function of the velocity ratio, which resulted in a tradeoff of acoustic energy between the two. Two sets of experimental measurements gathered at different laboratories were used to examine the validity of the model for a range of velocity and temperature in the core and fan streams. For the most part, the model was successful and provided a continuous transformation of the spectrum as the velocity profile changed from a normal to an inverted. The latter situation resulted in an enhancement of the high frequency noise from fan-stream sources that also led to a second peak in the spectrum.

Supersonic jets under imperfectly expanded conditions emit broadband shock associated noise that could dominate the high frequency turbulent mixing noise. A semi-empirical model for shock noise in single stream jets has been developed in Reference 12. It implements a power law similar to the jet mixing noise, but utilizes a so-called shock intensity parameter as the dependent variable. Similar efforts may be required in order to develop a semi-empirical model for shock noise in dual stream flows. Installation elements such as center plugs and pylons present additional parameters that demand consideration in the context of a comprehensive prediction model for noise in turbofan jet engines. 



\section{Appendix A.-Nozzle Discharge Coefficient and True Velocity}

Nozzle discharge coefficient $C_{d}$ is defined as the ratio of the actual mass flow rate through a nozzle to the ideal mass flow rate based on one-dimensional isentropic flow relations. We use subscripts $t$ and $i d$ to identify the actual (true) and ideal parameters, and superscript $o$ denotes the stagnation values as before.

$$
C_{d}=\frac{\dot{m}_{t}}{\dot{m}_{i d}}=\frac{(\rho V A)_{t}}{(\rho V A)_{i d}}
$$

In general, coefficient $C_{d}$ is measured experimentally and is a function of the overall operating pressure ratio, convergence angle in the nozzle, the effect of the nozzle lip and boundary layer thickness, that is, the actual flow area at the exit. Once the discharge coefficient $C_{d}$ and area ratio $C_{A}=A_{t} / A_{i d}$ are known, Equation (A1) determines the velocity coefficient $V_{t} / V_{i d}$. The density coefficient $\rho_{t} / \rho_{i d}$ may be expressed in terms of $V_{t}$ and $V_{i d}$ using the isentropic gas relations.

$$
\frac{\rho^{o}}{\rho}=\left(\frac{p^{o}}{p}\right)^{1 / \gamma}, \frac{\rho_{t}^{o}}{\rho_{t}}=\left(\frac{p_{t}^{o}}{p_{\infty}}\right)^{1 / \gamma}, \frac{\rho_{i d}^{o}}{\rho_{i d}}=\left(\frac{p_{i d}^{o}}{p_{\infty}}\right)^{1 / \gamma} \Rightarrow \frac{\rho_{t}^{o}}{\rho_{i d}^{o}} \frac{\rho_{i d}}{\rho_{t}}=\left(\frac{p_{t}^{o}}{p_{i d}^{o}}\right)^{1 / \gamma}
$$

From equation of state

$$
p_{i d}^{o}=\rho_{i d}^{o} R T_{o}, \quad p_{t}^{o}=\rho_{t}^{o} R T^{o}, \quad\left(\text { assumes } T_{t}^{o}=T_{i d}^{o}=T^{o}\right)
$$

Or,

$$
\frac{\rho_{t}^{o}}{\rho_{i d}^{o}}=\frac{p_{t}^{o}}{p_{i d}^{o}}
$$

Equations (A2) and (A4) show that

$$
\frac{\rho_{i d}}{\rho_{t}}=\left(\frac{p_{t}^{o}}{p_{i d}^{o}}\right)^{(1-\gamma) / \gamma}
$$

The relation between the nozzle pressure ratio and Mach number may be used to evaluate the right hand side of (A5)

$$
\frac{p_{i d}^{o}}{p_{\infty}}=\left(1-\frac{\gamma-1}{2} \frac{V_{i d}^{2}}{a_{o}^{2}}\right)^{-\gamma /(\gamma-1)}, \frac{p_{t}^{o}}{p_{\infty}}=\left(1-\frac{\gamma-1}{2} \frac{V_{t}^{2}}{a_{o}^{2}}\right)^{-\gamma /(\gamma-1)}, a_{o}^{2}=\gamma R T^{o}
$$

Here $a_{\mathrm{o}}$ denotes the sound speed at the stagnation temperature $T^{\circ}$. From (A6) we have 


$$
\left(\frac{p_{t}^{o}}{p_{i d}^{o}}\right)=\left(\frac{1-\frac{1}{2}(\gamma-1)\left(\frac{V_{t}}{a_{o}}\right)^{2}}{1-\frac{1}{2}(\gamma-1)\left(\frac{V_{i d}}{a_{o}}\right)^{2}}\right)^{-\gamma /(\gamma-1)}
$$

Equations (A1), (A5) and (A7) are now combined as

$$
C_{d}=\frac{V_{t}}{V_{i d}}\left(\frac{1-\frac{1}{2}(\gamma-1)\left(\frac{V_{i d}}{a_{o}}\right)^{2}}{1-\frac{1}{2}(\gamma-1)\left(\frac{V_{t}}{a_{o}}\right)^{2}}\right) C_{A}
$$

Equation (A8) solves for $V_{t}$ when other quantities are known. Once the NPR $=p_{i d}^{o} / p_{\infty}$ and stagnation temperature $T^{\circ}$ at the nozzle inlet are specified, the value of $\gamma$ at the exit static temperature is determined by iteration, and is assumed to remain unchanged due to subsequent adjustments in velocity from $V_{i d}$ to $V_{t}$.

Equation (A8) may be rearranged as

$$
x_{t}^{2}+z x_{t}-1=0 ; \quad z \equiv \frac{1-x_{i d}^{2}}{\left(C_{d} / C_{A}\right) x_{i d}}
$$

The relevant solution to the above quadratic equation is

$$
x_{t}=\sqrt{1+(z / 2)^{2}}-(z / 2)
$$

where

$$
x \equiv \sqrt{\frac{\gamma-1}{2}} \frac{V}{a_{o}}, \quad V_{t}=V_{i d} \frac{x_{t}}{x_{i d}}
$$

As an example, consider the nozzle inflow conditions $N P R=1.50, T^{\circ} / T_{\infty}=2.50, T_{\infty}=520{ }^{\circ} \mathrm{R}$, and discharge to contraction area ratio of $C_{d} / C_{A}=0.95$. The specific heat ratio $\gamma$ and the static temperature $T$ are determined as $\gamma=1.3704, T=1176^{\circ} \mathrm{R}$, and the ideal velocity is evaluated as $V_{i d}=1309 \mathrm{fps}$.

Subsequently Equation (A10) solves for the true velocity $V_{t}=1255 \mathrm{fps}$, and a density coefficient of 0.99 . 


\section{References}

1. Zorumski, W.E., "Aircraft Noise Prediction Program Theoretical Manual," NASA-TM-83199, Parts 1 and 2, 1982.

2. Stone, J.R., Krejsa, E.A., and Clark, B.J., "Jet Noise Modeling for Coannular Nozzles Including the Effects of Chevrons," NASA/CR-2003-212522, September 2003.

3. Stone, J.R., Krejsa, E.A., Clark, B.J., and Berton, J.J., "Jet Noise Modeling for Suppressed and Unsuppressed Aircraft in Simulated Flight," NASA/TM-2009-215524, March 2009.

4. Ahuja, K.K., and Bushell, K.W. "An Experimental Study of Subsonic Jet Noise and Comparison with Theory," J. Sound and Vibration, 30(3), pp. 317-341, 1973.

5. Fisher, M.J., Preston, G.A., and Mead, C.J., "A Modeling of the Noise from Simple Coaxial Jets, Part I: With Unheated Primary Flow," J. Sound and Vibration, 209(3), pp. 385-403, 1998.

6. Fisher, M.J., Preston, G.A., and Mead, C.J., "A Modeling of the Noise from Simple Coaxial Jets, Part II: With Heated Primary Flow," J. Sound and Vibration, 209(3), pp. 405-417, 1998.

7. Tester, B.J., and Fisher, M.J., "A Contribution to the Understanding and Prediction of Jet Noise Generation in Forced Mixers," AIAA-2004-2897, 2004.

8. Tester, B.J., and Fisher, M.J., "A Contribution to the Understanding and Prediction of Jet Noise Generation in Forced Mixers: Part II Flight Effects" AIAA-2005-3094, 2005.

9. Tester, B.J., and Fisher, M.J., "A Contribution to the Understanding and Prediction of Jet Noise Generation in Forced Mixers: Part III Applications" AIAA-2006-2542, 2006.

10. Bridges, J. and Brown, C.A., "Validation of the Small Hot Jet Rig for Jet Noise Research", AIAA Paper 2005-2846, May 2005.

11. Brown, C.A., and Bridges, J., "Small Hot Jet Acoustic Rig Validation," NASA/TM-2006-214234, 2006.

12. Khavaran, A., and Bridges, J., "Development of Jet Noise Power Spectral Laws Using SHJAR Data," AIAA Paper 2009-3378, 2009.

13. Khavaran, A., and Bridges, J., "Jet Noise Scaling in Dual Stream Nozzles," AIAA Paper 2010-3968, 2010.

14. Ko, N.W.M., and Kwan, S.H., "The Initial Region of Subsonic Coaxial Jets," J. Fluid Mechanics, 73(2), pp. 305-332, 1976.

15. Abramovich, N., The Theory of Turbulent Jets, M.I.T. Press, 1963.

16. Eldred, K.M., et al., "Far-field noise Generation by Coaxial Flow Jet Exhaust. 1. Detailed Discussion," Wyle Lab Report FAA-RD-71-101, 1971.

17. Khavaran A., and Kenzakowski, D.C., and Mielke-Fagan, A.F., "Hot Jets and Sources of Jet Noise," International J. Aeroacoustics, 9(4, 5), pp. 491-532, 2010.

18. Larson, S.R., Nelson, D.P., and Stevens, B.S. "Aerodynamic and Acoustic Investigation of Inverted Velocity Profile Coannular Exhaust Nozzles Models and Development of Aerodynamic and Acoustic Prediction Procedures," NASA-CR-3168, 1979.

19. Kozlowski, H., and Packman, A.B., "Aerodynamics and Acoustic Tests of Duct-Burning Turbofan Exhaust Nozzles,” NASA CR-2628, Dec. 1976.

20. Kozlowski, H., and Packman, A.B., "Aeroacoustics Tests of Duct-Burning Turbofan Exhaust Nozzle - Comprehensive Data Report Vol. 1-Model Scale Acoustic Data," NASA CR-134910, Feb. 1977. 


\begin{tabular}{|c|c|c|}
\hline \multicolumn{2}{|c|}{ REPORT DOCUMENTATION PAGE } & $\begin{array}{l}\text { Form Approved } \\
\text { OMB No. 0704-0188 }\end{array}$ \\
\hline \multicolumn{3}{|c|}{ 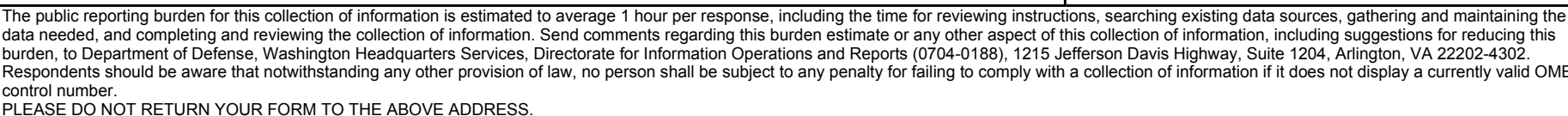 } \\
\hline $\begin{array}{l}\text { 1. REPORT DATE (DD-MM-YYYY) } \\
01-02-2012\end{array}$ & $\begin{array}{l}\text { 2. REPORT TYPE } \\
\text { Technical Memorandum }\end{array}$ & 3. DATES COVERED (From - To) \\
\hline \multirow{3}{*}{\multicolumn{2}{|c|}{$\begin{array}{l}\text { 4. TITLE AND SUBTITLE } \\
\text { Acoustic Investigation of Jet Mixing Noise in Dual Stream Nozzles }\end{array}$}} & 5a. CONTRACT NUMBER \\
\hline & & 5b. GRANT NUMBER \\
\hline & & 5c. PROGRAM ELEMENT NUMBER \\
\hline \multirow{3}{*}{\multicolumn{2}{|c|}{$\begin{array}{l}\text { 6. AUTHOR(S) } \\
\text { Khavaran, Abbas; Dahl, Milo, D. }\end{array}$}} & 5d. PROJECT NUMBER \\
\hline & & 5e. TASK NUMBER \\
\hline & & $\begin{array}{l}\text { 5f. WORK UNIT NUMBER } \\
\text { WBS 561581.02.08.03.18.03 }\end{array}$ \\
\hline \multicolumn{2}{|c|}{$\begin{array}{l}\text { 7. PERFORMING ORGANIZATION NAME(S) AND ADDRESS(ES) } \\
\text { National Aeronautics and Space Administration } \\
\text { John H. Glenn Research Center at Lewis Field } \\
\text { Cleveland, Ohio 44135-3191 }\end{array}$} & $\begin{array}{l}\text { 8. PERFORMING ORGANIZATION } \\
\text { REPORT NUMBER } \\
\text { E-17909 }\end{array}$ \\
\hline \multirow{2}{*}{\multicolumn{2}{|c|}{$\begin{array}{l}\text { 9. SPONSORING/MONITORING AGENCY NAME(S) AND ADDRESS(ES) } \\
\text { National Aeronautics and Space Administration } \\
\text { Washington, DC 20546-0001 }\end{array}$}} & $\begin{array}{l}\text { 10. SPONSORING/MONITOR'S } \\
\text { ACRONYM(S) } \\
\text { NASA }\end{array}$ \\
\hline & & $\begin{array}{l}\text { 11. SPONSORING/MONITORING } \\
\text { REPORT NUMBER } \\
\text { NASA/TM-2012-217226 }\end{array}$ \\
\hline \multicolumn{3}{|c|}{$\begin{array}{l}\text { 12. DISTRIBUTION/AVAILABILITY STATEMENT } \\
\text { Unclassified-Unlimited } \\
\text { Subject Category: } 71 \\
\text { Available electronically at http://www.sti.nasa.gov } \\
\text { This publication is available from the NASA Center for AeroSpace Information, 443-757-5802 }\end{array}$} \\
\hline
\end{tabular}

\section{SUPPLEMENTARY NOTES}

\section{ABSTRACT}

In an earlier study, a prediction model for jet noise in dual stream jets was proposed that is founded on velocity scaling laws in single stream jets and similarity features of the mean velocity and turbulent kinetic energy in dual stream flows. The model forms a composite spectrum from four component single-stream jets each believed to represent noise-generation from a distinct region in the actual flow. While the methodology worked effectively at conditions considered earlier, recent examination of acoustic data at some unconventional conditions indicate that further improvements are necessary in order to expand the range of applicability of the model. The present work demonstrates how these predictions compare with experimental data gathered by NASA and industry for the purpose of examining the aerodynamic and acoustic performance of such nozzles for a wide range of core and fan stream conditions. Of particular interest are jets with inverted velocity and temperature profiles and the appearance of a second spectral peak at small aft angles to the jet under such conditions. It is shown that a four-component spectrum succeeds in modeling the second peak when the aft angle refraction effects are properly incorporated into the model. A tradeoff of noise emission takes place between two turbulent regions identified as transition and fully mixed regions as the fan stream velocity exceeds that of the core stream. The effect of nozzle discharge coefficients will also be discussed.

\section{SUBJECT TERMS}

Noise; Aircraft noise; Aerodynamic noise; Acoustics

\begin{tabular}{|c|c|c|c|c|c|}
\hline \multicolumn{3}{|c|}{ 16. SECURITY CLASSIFICATION OF: } & \multirow{2}{*}{$\begin{array}{l}\text { 17. LIMITATION OF } \\
\text { ABSTRACT } \\
\text { UU }\end{array}$} & \multirow{2}{*}{$\begin{array}{l}\text { 18. NUMBER } \\
\text { OF } \\
\text { PAGES } \\
31\end{array}$} & \multirow{2}{*}{$\begin{array}{l}\text { 19a. NAME OF RESPONSIBLE PERSON } \\
\text { STI Help Desk (email:help@sti.nasa.gov) } \\
\text { 19b. TELEPHONE NUMBER (include area code) } \\
\text { 443-757-5802 }\end{array}$} \\
\hline $\begin{array}{l}\text { a. REPORT } \\
U\end{array}$ & $\begin{array}{l}\text { b. ABSTRACT } \\
\mathrm{U}\end{array}$ & $\begin{array}{l}\text { c. THIS } \\
\text { PAGE } \\
\text { U }\end{array}$ & & & \\
\hline
\end{tabular}


